\title{
Proposal of Physical-Statistical Model of Thermal Aging Respecting Threshold Value
}

\author{
Jakub Souček ${ }^{1}$, Pavel Trnka ${ }^{2, *}$ (i) and Jaroslav Hornak ${ }^{2}$ \\ 1 ALFMEIER CZ s.r.o., 30100 Pilsen, Czech Republic; Jakub.Soucek@alfmeier.cz \\ 2 Department of Technologies and Measurement, Faculty of Electrical Engineering, University of West \\ Bohemia, 30614 Pilsen, Czech Republic; jhornak@ket.zcu.cz \\ * Correspondence: pavel@ket.zcu.cz; Tel.: +420-377-634-518
}

Received: 26 June 2017; Accepted: 24 July 2017; Published: 2 August 2017

\begin{abstract}
The aging of electrical insulation material or a system is a main issue for designers of high-voltage (HV) machines. Precise determination of the life cycle of electrical insulation is one way of improving the efficiency of electrical machines involved in the production and transmission of electrical energy. Much effort has been devoted to preparing statistical or physical methods of Electrical Insulating System (EIS) life time estimation in the real operation of electrical machinery. The main aim of this paper is to introduce a new physical-statistical model of thermal aging respecting the threshold value. This model is based on thermal aging model and the main difference between this model and previously published models is taking into account the threshold value of degradation factor. The complete design of this model is presented in this paper, including functions defining the threshold value of the effect of the degradation factor depending on the temperature. Proposed model was verified by accelerated thermal aging test at selected temperatures $\left(160,170,180^{\circ} \mathrm{C}\right)$ and time intervals $(0,120,240 \mathrm{~h})$ on a commonly used transformer board. The breakdown voltage was set as an indicating parameter of the level of thermal aging and was measured according to standard IEC 60243-1. Collected data from these measurements were used for threshold value determination $(431.23 \mathrm{~K})$ and verification of proposed physical-statistical model of thermal aging respecting the threshold value.
\end{abstract}

Keywords: aging model; insulation; Weibull distribution; threshold value

\section{Introduction}

Aging models are commonly used to describe the degradation processes inside the electric insulating system (EIS) [1-6]. The degradation of the insulation system is dependent on the understanding of the physicochemical processes and on the mathematical description of the aging macroscopic parameters or empirical constants commonly used in aging models. Sometimes, statistics [7-9] are used to estimate the mean time to failure (MTTF), etc. However, a more concrete model of aging can be designed when all degradation processes are fully understood. Certain degradation factors acting in a concrete EIS can be identified, such as electric field intensity [10-13], temperature [14-17], mechanical stress [18], radiation [19], moisture [20], dust [21], chemical stress [22], etc. and including these degradation mechanisms into a single model would be impossible. For this reason, it is difficult to design aging models that are well correlated with the actual condition and include the factors that contribute most to degradation. Models of aging can be divided into various groups as seen in Figure 1. This paper extends, complements and partially corrects the theories presented in Reference [23]. 


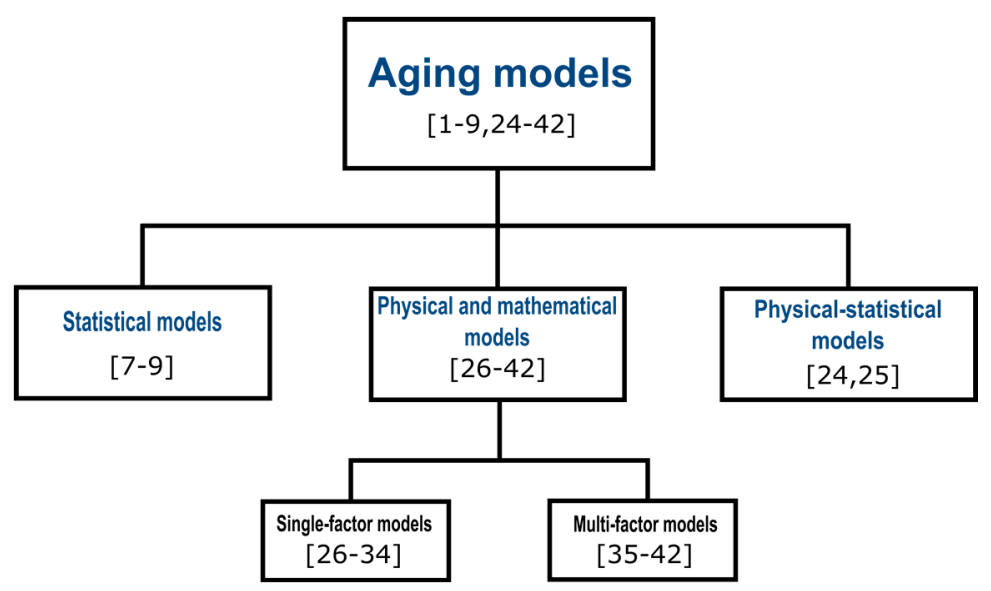

Figure 1. Different mathematical approaches to aging modeling [1-9,24-42].

The main aim of this paper is to include a threshold for calculations based on mathematical-physical presumptions. The proposed model would provide information on the probability of failure during the variable degradation factor. Verification of presented model was performed on samples of thermally aged electrical insulation (EI) by breakdown voltage (BDV) measurement. The constants and variables used in this paper are described in detail in Appendix A.

\subsection{Example of Statistical Access}

In terms of the operation, design, and production of an electrical device, it is necessary to understand not only the physical principles of degradation and the behavior of its individual elements, but also the lifetime model of these elements using probabilistic expressions and the statistical behavior of its parameters. To ensure the proper function of electrical devices, it is necessary to guarantee trouble-free operation. Using reliability theory, the reliability of an observed system can be predicted by mathematical models, and the critical points of the system can be found. Currently, statistical and mathematical models based on statistical distributions are used for the analysis of reliability. The distributions primarily used for this purpose are the Weibull [43], Exponential [44], or Normal distribution [45]. The Weibull distribution is used in cases where the investigated object cannot accept the assumption of a constant failure rate. The Weibull distribution is used to describe the reliability of electrical devices where the reliability of these systems and their subsystems depends on the number of operational hours, age, or a number of cycles performed. The probability density of the two-parameter Weibull distribution is given by Equation (1).

$$
f(t)=\frac{\beta}{\eta} \cdot\left(\frac{t}{\eta}\right)^{\beta-1} \cdot e^{-\left(\frac{t}{\eta}\right)^{\beta}}, \text { for } t \geq 0
$$

where $\beta$ is the shape parameter and $\eta(h)$ is the scale parameter, which determines the scale on the timeline.

The parameter $\beta$ affects the shape of the resulting distribution. If $\beta<1$, then the instantaneous failure rate decreases; if $\beta>1$, then the instantaneous failure rate increases. A special case is $\beta=1$, where the Weibull distribution is equivalent to the exponential distribution and the instantaneous failure rate becomes constant. These limit values of the parameter $\beta$ are characteristic for the construction of the bathtub curve [43].

The cumulative distribution function (CDF) [46-48] is introduced for further calculations. The numerical expression uses the probability of a fault condition, which is defined as the area under the 
curve of probability density function and the probability that the investigated object fails in time $t$, see Equation (2).

$$
F(t)=\int_{0}^{t} f(\tau) \mathrm{d} \tau=1-e^{-\left(\frac{t}{\eta}\right)^{\beta}}
$$

where $F(t)$ is the cumulative distribution function.

The next important statistical variable is the MTTF. The MTTF is a statistical variable used to assess the reliability of electrical devices and is calculated using Equation (3) [43]

$$
\operatorname{MTTF}=\eta \cdot \Gamma\left(1+\frac{1}{\beta}\right)
$$

where $\Gamma(z)$ is calculated by Equation (4). Each value of the function $\Gamma(z)$ is given in standard IEC 61649 [43], which involves Weibull analysis.

$$
\Gamma(z)=\int_{0}^{\infty} t^{z-1} e^{-t} \mathrm{~d} t
$$

For proper use of this distribution, it is necessary to make an accurate estimation of the parameters. Most commonly, estimation of the parameters of the Weibull distribution involves the maximum likelihood (MLE) method and the probability chart, which is used for visual inspection.

The Weibull distribution is commonly used on electric insulation data $[1,7,8]$, e.g., times to failure in the case of the electrical aging test. The limitation of the statistical approach is that it provides the probability of object failure only when sufficient statistical data is available and is of the same degradation in the case of the test. These results give no information about the state of a certain object, which can be important in electrical engineering (e.g., the probability of failure of a large transformer vs. real state/condition of that transformer).

\subsection{Use of Physical and Mathematical Models}

The physical models of material aging can be divided into empirical and phenomenological models. These models can be further divided based on the number of active degradation factors to single-factor and multi-factor models.

Only one degradation factor is included in single-factor models of EIS aging. The most important single-factor models can be further divided into:

- Electrical aging models [26-28],

- Thermal aging models [29-33],

- Mechanical aging models [34].

Multifactor models are objects of research, as seen in References [35-42]. In cases where the insulation system is exposed to more than one degradation mechanism simultaneously, a substantial reduction of lifetime occurs, compared to when it is exposed to these degradation mechanisms in insulation. The resulting model will not necessarily be the algebraic sum of these degradation effects. Two basic types of interactions are known: direct and indirect [36]. These interactions must be considered for the multifactor model. Currently, there are many multifactorial models that are based on the simultaneous action of electrical, thermal, or mechanical stress as discussed in References [37,38]. These models are mostly empirical in character; however, there are also models that have a physical character [36]. In the following, the effort has been made to develop a model that will employ both statistical and physical factors and will respect the phenomenon of the threshold for the degradation factor. 


\subsection{Thermal Aging Models}

Temperature is one of the most significant degradation factors [29-33]. Irreversible physicochemical processes occur in the insulation system due to thermal stress, which may subsequently degrade the dielectric properties of these systems by increasing the electrical conductivity or dissipation factor. For this reason, materials with approximately identical thermal properties are categorized in thermal classes given in standard EN 60085 [49].

Montsinger see Reference [32], first attempted to provide a mathematical formulation of thermal aging and found that the experimental results may be expressed by an exponential function, which indicates the dependence of the lifetime on the temperature (Equation (5)).

$$
\tau(T)=A \cdot e^{-B T}
$$

where $A(\mathrm{~h})$ and $B\left(\mathrm{~K}^{-1}\right)$ are material constants; $T$ is the temperature $\left({ }^{\circ} \mathrm{C}\right)$; and $\tau$ is the lifetime (h).

The disadvantage of this model is that it is empirical and does not describe the insulation system in terms of physicochemical processes. Dakin [33], attempted to address this disadvantage and set the mechanism of thermal aging using the Arrhenius equation (see Equation (6))

$$
k=A^{*} \cdot e^{-\frac{E_{a}}{\mathrm{R} T}}
$$

where $k$ is the reaction rate $\left(\mathrm{s}^{-1}\right) ; A^{*}$ is the pre-exponential factor or frequency factor $\left(\mathrm{s}^{-1}\right) ; T$ is the absolute temperature $(\mathrm{K})$; $E_{a}$ is the activation energy $\left(\mathrm{J} \cdot \mathrm{mol}^{-1}\right)$; and $\mathrm{R}$ is the universal gas constant, which has a value of $8.3144598 \mathrm{~J} \cdot \mathrm{K}^{-1} \cdot \mathrm{mol}^{-1}$.

This equation describes the dependence of the reaction rate of the material on the temperature and shows that an increase of temperature must inevitably increase the reaction rate, which is caused by applying additional energy via heating of the material [50,51].

Assuming that increasing the temperature will decrease the lifetime of the insulation system, the model of thermal aging can be written as follows, Equation (7) [33,50].

$$
\tau(T)=a \cdot e^{\frac{E_{a}}{R T}}=a \cdot e^{\frac{b}{T}}
$$

where $\tau$ is the lifetime of the insulation system (h); and $a$ and $b$ are material constants. The value of $a$ is given as the reciprocal value of the pre-exponential factor $A^{*}$, which represents the frequency of clashing molecules.

\subsection{Electrical Aging Models}

The intensity of an electric field is another major degradation factor that significantly affects insulation systems [26-28]. The mechanism of action of the electric field on the insulation structure is yet to be fully understood. Currently, only empirical models based on experimental observations are used, of which the power and exponential models are the most commonly used electrical aging models [35,36].

The power model is one of the most commonly used models for the description of electrical aging and is given by Equation (8) [9].

$$
\begin{gathered}
\tau(E)=k \cdot E^{-N} \\
\ln \tau=\ln k-N \ln E
\end{gathered}
$$

where $\tau$ is the lifetime of the insulation system (h) (this value is usually equal to $\eta$ parameter from Weibull distribution); $E$ is the intensity of the electric field $\left(\mathrm{kV} \cdot \mathrm{mm}^{-1}\right)$; and $k\left(\mathrm{kV}^{-1} \cdot \mathrm{mm} \cdot \mathrm{h}\right)$ and $N$ 
are material constants, which must be determined empirically. The exponential model is another often-used model of electrical aging, which is given by Equation (9) [9].

$$
\begin{gathered}
\tau(E)=c^{*} \cdot e^{-b E} \\
\ln \tau=\ln c^{*}-b E
\end{gathered}
$$

where $\tau$ is the lifetime of the insulation system (h); $E$ is the intensity of the electric field $\left(\mathrm{kV} \cdot \mathrm{mm}^{-1}\right)$; and $b\left(\mathrm{kV}^{-1} \cdot \mathrm{mm}\right)$ and $c^{*}(\mathrm{~h})$ are constants, which must be determined empirically from experimental data.

The above-mentioned models describe the aging of any material exposed to the electric field. For these models, it is not necessary to understand all the electric-field related processes affecting the material, or other circumstances such as the presence of partial discharges. Furthermore, these models are not dependent on the structure or configuration of the electrode, and electric field distribution. Equations (8) and (9) are the only empirically derived models that describe the influence of electric field strength on the aging of an insulation system. Despite this fact, these models provide relatively good results and the calculated lifetime corresponds with reality. These models, however, fail when the aging mechanism is changed e.g., at lower levels of electric field intensity. This discrepancy is explained by the theory that there is a threshold intensity below the electric field that does not affect material aging.

It is necessary to validate this model by plotting of the measured data into a semi-logarithmic plot (Figure 2). If the measured data lie on one line, as seen in Figure 2 as a dashed line, then the predicted use of the exponential model of electric aging is correct [35].

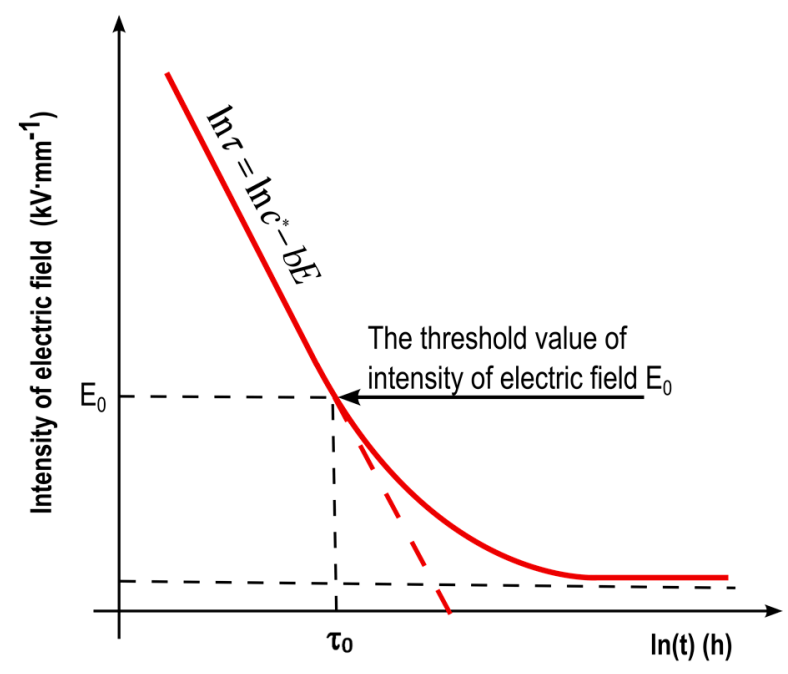

Figure 2. Exponential function of electrical aging plotted in semi-logarithmic scale (Redraw and adapted figure from [35]).

Problems with both models can occur due to extrapolating the measured data in actual operating conditions. By assuming that an electric field will not cause aging at low levels of stress (e.g., nominal voltage) $[10,11]$, the service life extrapolated from the measured aging curves will be significantly lower than reality. This fact can be removed by introducing a threshold value, as shown in Figure 2, and various models of electric aging are therefore adjusted. Modified equations of the power model [9] and the exponential model [13] are shown in Equations (10) and (11), respectively.

$$
\begin{gathered}
\tau(E)=\tau_{0} \cdot\left(\frac{E}{E_{0}}\right)^{-N} \\
\tau(E)=\frac{X_{2}}{E-E_{0}} \cdot e^{\left[-X_{1}\left(E-E_{0}\right)\right]}
\end{gathered}
$$


where $E$ is the intensity of electric field $\left(\mathrm{kV} \cdot \mathrm{mm}^{-1}\right) ; \tau_{0}(\mathrm{~h})$ is the lifetime of the insulation system for threshold value $E_{0}\left(\mathrm{kV} \cdot \mathrm{mm}^{-1}\right) ; X_{1}\left(\mathrm{kV} \cdot \mathrm{mm}^{-1}\right)$ and $X_{2}\left(\mathrm{kV} \cdot \mathrm{mm}^{-1} \cdot \mathrm{h}\right)$ are constants, which must be determined empirically from experiments.

Numerous models have been introduced in the past including Montanari [24], Dissado [27], Crine [34], Simoni [37], Fallou [40] and Grzybowski [42]. Some of these models are empirical, and some are more physical. The presented models include single factor and multifactor models. These models can be used for the description of aging of EIS by electrical (DC, AC or pulse), thermal, or mechanical stress, but within certain limits.

\section{Physical-Statistical Model of Thermal Aging Respecting Threshold Value (Thermal Aging Model Respecting the Threshold (TAMRT))}

Currently, there are efforts to create an endurance model of an electrical insulation system for selected degradation mechanisms that would entirely correspond with the real situation. This model should be simple and applicable in practice for on-line monitoring of the residual life of electrical insulation systems and electrical equipment. In the event that this model should correspond to reality, it must include the threshold value of the effect of the degradation factor. In the model of thermal aging, a temperature $T_{T}(\mathrm{~K})$ is introduced. Before the attainment of $T_{T}$ takes place, different degradation mechanisms other than the described provisional models. The proposed model assumes that at low levels, the effects of degradation mechanisms aging in the insulation system almost do not occur. However, other degradation mechanisms can occur and a description of the degradation of electrical insulation systems is dependent on the best possible understanding of the physicochemical processes. The better the understanding of these processes is, a more specific aging model can be built.

\subsection{Model Suggestion}

The proposed model assumes an infinite number of limit states. When this "state" is exceeded, other degradation mechanisms operate differently than described by Equation (7). Limit states are consequently characterized by temperature limits $T_{T 1}$ up to $T_{T n}$ and partial activation energies $E_{a 1}$ to $E_{a n}$. Activation energy $E_{a 1}$ up to $E_{a n}$ therefore define partial degradation mechanisms and characterize aging electrical insulating system at intervals of extreme temperatures $T_{T 1}$ up to $T_{T n}$. The graphical representation of this assumption in logarithmic axes is shown in Figure 3.

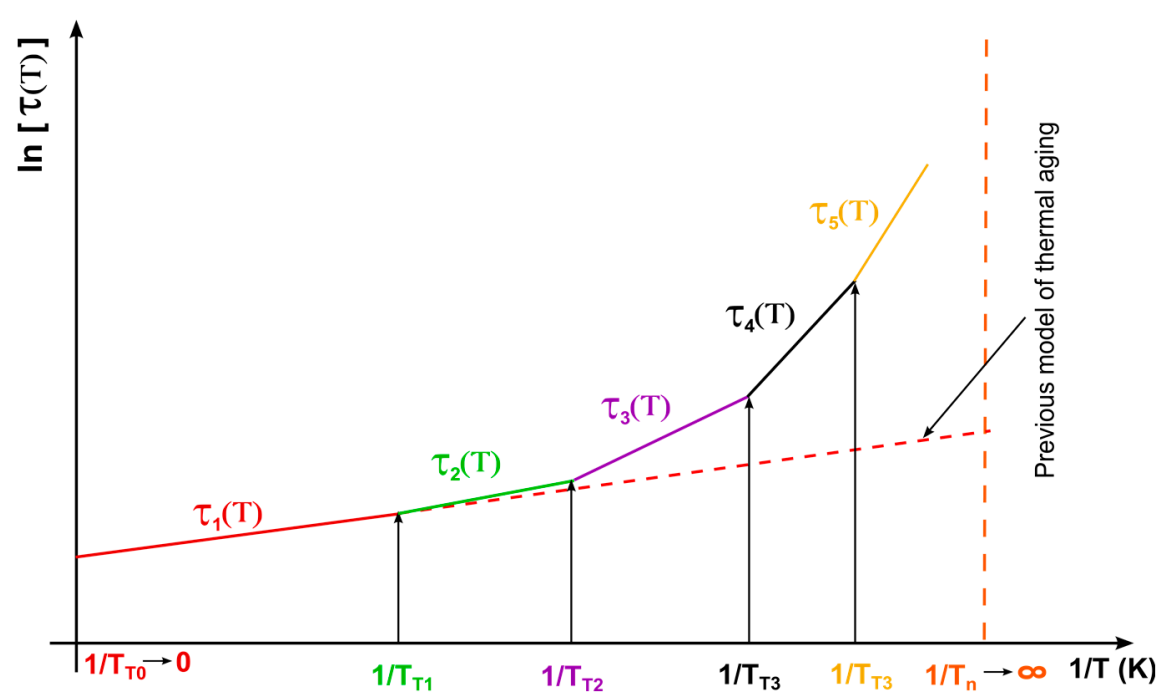

Figure 3. Graphical representation of the proposed model in logarithmic scale. 
With this assumption, the model of thermal aging can be written with respect to the threshold value as a prescription of a function of the lifetime, see Equation (12).

$$
\begin{gathered}
\tau(T)=\tau_{1}=K_{1} \cdot a \cdot \tau_{T 1}, T \in\left\langle T_{T 1}, \infty\right) \\
\tau(T)=\tau_{2}=K_{2} \cdot a \cdot \tau_{T 2}, T \in\left\langle T_{T 2}, T_{T 1}\right) \\
\vdots \\
\tau(T)=\tau_{n}=K_{n} \cdot a \cdot \tau_{T n}, T \in\left(0, T_{T(n-1)}\right)
\end{gathered}
$$

where $\tau_{i}(\mathrm{~h})$, for $i=(1$ to $n)$, is the life of an electrical insulating system within the temperature range, based on Equation (7) (see Equation (13)); and $K_{i}$ is a correction parameter for the preservation conditions, see Equation (14).

$$
\tau_{i}=K_{i} \cdot a \cdot \tau_{T i}=K_{i} \cdot a \cdot e^{\frac{E_{a i}}{\mathrm{R} T}}, T \in\left\langle T_{T i}, T_{T(i-1)}\right)
$$

where $a(\mathrm{~h})$ is the reciprocal value of pre-exponential factor; $T$ is the temperature $(\mathrm{K}) ; E_{a i}$ is the activation energy of the partial degradation mechanism $\left(\mathrm{J} \cdot \mathrm{mol}^{-1}\right)$, see Table 1.

$$
K_{i}=\frac{\tau_{T(i-1)}\left(T_{T(i-1)}\right)}{\tau_{T i}\left(T_{T(i-1)}\right)}
$$

where $K_{1}$ is determined by Equation (15)

$$
K_{1}=\frac{\tau_{T 0}\left(T_{T 0}\right)}{\tau_{T 1}\left(T_{T 0}\right)}=\frac{1}{1}=1 \text { for } T_{T 0} \rightarrow \infty
$$

Table 1. Parameter values characterizing the designed thermal aging model for partial degradation mechanisms.

\begin{tabular}{cccccc}
\hline $\boldsymbol{i}$ & Interval of $\boldsymbol{T}_{\boldsymbol{i}} \mathbf{( K )}$ & $\boldsymbol{T}_{\boldsymbol{T} \boldsymbol{i}}(\mathbf{K})$ & $\boldsymbol{o}_{\boldsymbol{i}} \mathbf{( h )}$ & $\boldsymbol{E}_{\boldsymbol{a} \mathbf{i}}\left(\mathbf{J} \cdot \mathbf{m o l}^{\mathbf{- 1}}\right)$ & $\boldsymbol{K}_{\boldsymbol{i}}$ \\
\hline $\mathbf{1}$ & $T \in\left\langle T_{T 1}, \infty\right)$ & $\infty$ & $\tau_{1}=K_{1} \cdot a \cdot \tau_{T 1}=K_{1} \cdot a \cdot e^{\frac{E_{a 1}}{R T}}$ & $E_{a 1}$ & $K_{1}=\frac{\tau_{T 0}\left(T_{T 0}\right)}{\tau_{T 1}\left(T_{T 0}\right)}=1$ \\
\hline $\mathbf{2}$ & $T \in\left\langle T_{T 2}, T_{T 1}\right)$ & $T_{T 1}$ & $\tau_{2}=K_{2} \cdot a \cdot \tau_{T 2}=K_{2} \cdot a \cdot e^{\frac{E_{a 2}}{R T}}$ & $E_{a 2}$ & $K_{2}=\frac{\tau_{T 1}\left(T_{T 1}\right)}{\tau_{T 2}\left(T_{T 1}\right)}$ \\
\hline $\mathbf{3}$ & $T \in\left\langle T_{T 3}, T_{T 2}\right)$ & $T_{T 2}$ & $\tau_{3}=K_{3} \cdot a \cdot \tau_{T 3}=K_{3} \cdot a \cdot e^{\frac{E_{a 3}}{R T}}$ & $E_{a 3}$ & $K_{3}=\frac{\tau_{T 2}\left(T_{T 2}\right)}{\tau_{T 3}\left(T_{T 2}\right)}$ \\
\hline & & $\vdots$ & & \\
\hline $\boldsymbol{n}$ & $T \in\left(0, T_{T(n-1)}\right)$ & $T_{T(n-1)}$ & $\tau_{n}=K_{n} \cdot a \cdot \tau_{T n}=K_{n} \cdot a \cdot e^{\frac{E_{a n}}{R T}}$ & $E_{a n}$ & $K_{n}=\frac{\tau_{T(n-1)}\left(T_{T(n-1)}\right)}{\tau_{T n}\left(T_{T(n-1)}\right)}$ \\
\hline
\end{tabular}

It is, therefore, clear that the equation passes in classical Büssing's relationship, see Equation (7). It is clear that the results of partial degradation mechanisms in a logarithmic scale, before reaching the limits of the influence of the degradation factor, are exponential in nature. The resulting trend of the thermal aging model with respect to the limit value is shown in Figure 4.

Modified thermal aging model $\tau_{M}(T)$, for $T \in\left(0, T_{T 1}\right)$ is then characterized by Equation (16)

$$
\tau_{M}(T)=K_{M} \cdot a \cdot \tau_{T M}=K_{M} \cdot a \cdot e^{\left(\frac{D}{T}\right)}, T \in\left(0, T_{T 1}\right)
$$


where $\tau_{M}(\mathrm{~h})$ is a modified model of thermal aging; $D(\mathrm{~K})$ is a material constant, which is characterized by synergistic effect of partial degradation mechanisms; $a(\mathrm{~h})$ is the reciprocal value of pre-exponential factor; $K_{M}$ is a correction parameter for the preservation conditions and it is given by Equation (17).

$$
K_{M}=\frac{\tau_{T 1}\left(T_{T 1}\right)}{\tau_{T M}\left(T_{T 1}\right)}=\frac{e^{\left(\frac{E_{a 1}}{R T_{T 1}}\right)}}{e^{\left(e^{\left(\frac{D}{T T 1}\right)}\right)}}=e^{\left[\left(\frac{E_{a 1}}{R T_{T 1}}\right)-e^{\left(\frac{D}{T} T_{T 1}\right.}\right]}
$$

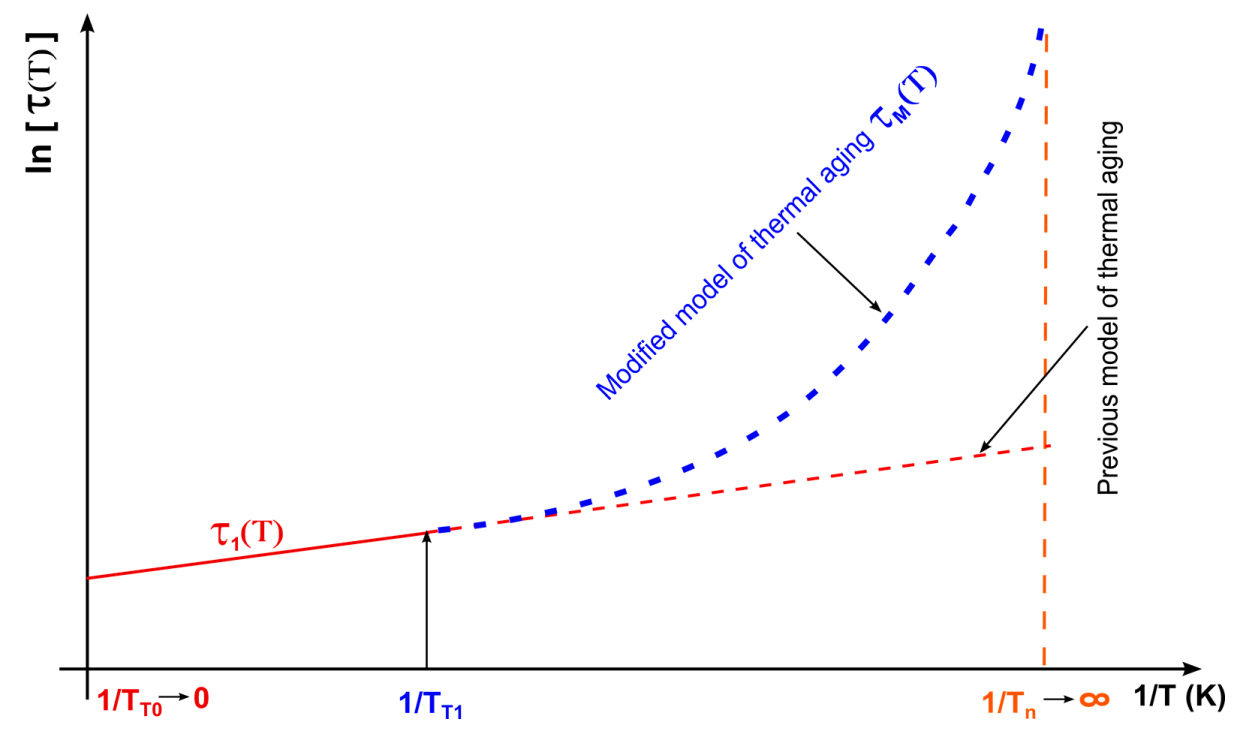

Figure 4. The course of thermal aging model that respects limit state of the effect of the degradation factor in logarithmic scale.

If models of aging $\left(\tau_{1}(T)\right.$ for temperature interval $T \in\left\langle T_{T 1}, \infty\right)$ and $\tau_{M}(T)$ for the interval of temperatures $\left.T \in\left(0, T_{T 1}\right)\right)$ that define partial degradation mechanisms are known, the resulting model of thermal aging can be written with respect to the threshold value as Equation (18).

$$
\begin{gathered}
\tau(T)=\tau_{1}=K_{1} \cdot a \cdot \tau_{T 1}=K_{1} \cdot a \cdot e^{\frac{E_{a 1}}{R T}}=a \cdot e^{\frac{E_{a 1}}{R T}}, T \in\left\langle T_{T 1}, \infty\right) \\
\tau(T)=\tau_{M}=K_{M} \cdot a \cdot \tau_{T M}=K_{M} \cdot a \cdot e^{e^{\left(\frac{D}{T}\right)}}=e^{\left[\left(\frac{E_{a 1}}{R T T 1}\right)-e^{\left(\frac{D}{T} T\right)}\right]} \cdot a \cdot e^{\left(e^{\left(\frac{D}{T}\right)}\right.}, T \in\left(0, T_{T 1}\right)
\end{gathered}
$$

Model (Equation (16)) can be further simplified by introducing a function $B(T)$ and $C(T)$ defining the threshold value of the effect of the degradation factor $T_{T 1}$ depending on the temperature $T$. The resulting model (Equation (16)) is then entered as Equation (19):

$$
\begin{aligned}
& \tau(T)=a \cdot K_{M} B(T) \cdot e^{\frac{E_{a 1} \cdot C(T)}{R T}} \cdot e^{B(T) \cdot e^{\left(\frac{D}{T}\right)}}=a \cdot K_{M}^{B(T)} \cdot e^{\left[\left(\frac{E_{a 1} \cdot C(T)}{R T}\right)+B(T) \cdot e^{\left(\frac{D}{T}\right)}\right]}= \\
& a \cdot e^{\left[\left(\frac{E_{a 1} \cdot B(T)}{R T T 1}\right)-B(T) \cdot e^{\left(\frac{D}{T} T 1\right.}\right)} \cdot e^{\left[\left(\frac{E_{a 1} \cdot C(T)}{R T}\right)+B(T) \cdot e^{\left(\frac{D}{T}\right)}\right]}= \\
& a \cdot e^{\left.\left[\left(\frac{E_{a 1} \cdot C(T)}{R T}\right)+\left(\frac{E_{a 1} \cdot B(T)}{R T_{T 1}}\right)+B(T) \cdot e^{\left(\frac{D}{T}\right)}-e^{\left(\frac{D}{T T 1}\right)}\right]\right]}=a \cdot e^{\left.\left[\left(\frac{E_{a 1} \cdot\left(C(T) \cdot T_{T 1}+B(T) \cdot T\right)}{R \cdot T \cdot T}\right)+B(T) \cdot e^{\left(\frac{D}{T}\right)}-e^{\left(\frac{D}{T T 1}\right)}\right]\right]}
\end{aligned}
$$

where $B(T)$ and $C(T)$ are functions defining the threshold value of the effect of the degradation factor $T_{T 1}$ depending on the temperature $T$, for which you apply $B(T)=0 ; C(T)=1$ for $T \in\left\langle T_{T 1}, \infty\right)$ and $B(T)=1 ; C(T)=0$ for $T \in\left(0, T_{T 1}\right)$.

\subsection{Determining the Threshold Value $T_{T}$ Using a Probabilistic Model}

For a description of times to failure of an electrical insulating system, a distribution function is used (Equation (20)). The parameter $\eta=\eta(T)$ is then characterized by the proposed model of thermal 
aging with respect to the threshold of the effect of the degradation factor (Equation (21)). A more detailed derivation of the statistical model is described in Reference [24].

$$
\begin{gathered}
F(t, T)=\int_{0}^{t} f(t) d t=1-e^{-\left(\frac{t}{\eta(T)}\right)^{\beta(T)}} \\
\eta(T)=a \cdot K_{M}{ }^{B(T)} \cdot e^{\frac{E_{a 1} \cdot C(T)}{R T}} \cdot e^{B(T) \cdot e^{\left(\frac{D}{T}\right)}=} \\
a \cdot e^{\left.\left[\left(\frac{E_{a 1} \cdot\left(C(T) \cdot T_{T 1}+B(T) \cdot T\right)}{R \cdot T \cdot T}\right)+B(T) \cdot\left[e^{\left(\frac{D}{T}\right)}-e^{\left(\frac{D}{T} T 1\right.}\right)\right]\right]}
\end{gathered}
$$

where $K_{M}$ is a correction parameter for the preservation conditions $\tau_{1}\left(T_{T 1}\right)=\tau_{M}\left(T_{T 1}\right) ; \beta(T)$ is a function of the shape parameter of the Weibull distribution depending on the temperature $T(\mathrm{~K})$ and $t(\mathrm{~h})$ is the time to failure of the electro-insulation system. Substituting Equation (21) into Equation (20), the proposed probabilistic model can be written as Equation (22).

$$
\begin{gathered}
F(t, T)=\int_{0}^{t} f(t) \mathrm{d} t=1-e^{-\left(\frac{t}{\eta(T)}\right)^{\beta(T)}}= \\
1-e^{-\left(\frac{t}{a} \cdot e^{\left.-\left[\left(\frac{E_{a 1} \cdot\left(C(T) \cdot T_{T 1}+B(T) \cdot T\right)}{R \cdot T \cdot T}\right)+B(T) \cdot\left[e^{\left(\frac{D}{T}\right)}-e^{\left(\frac{D}{T} T 1\right.}\right)\right]\right]}\right)}
\end{gathered}
$$

The probability density of the proposed probabilistic model is then defined as the first derivative of the distribution function (Equation (20)) based on time and is given in Equation (23).

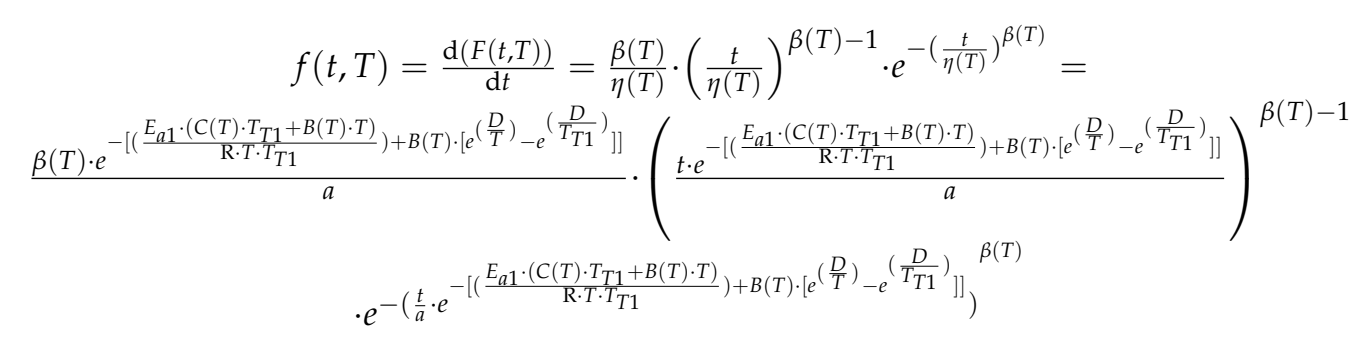

Determination of the threshold value of the effect of the degradation factor $T_{T 1}$ is based on the above proposed probabilistic model (Equation (22)). For further considerations, variable $\lambda(t, T)$, which characterizes the intensity of failures depending on the temperature $T$ and time $t$ is introduced and is given by Equation (24).

$$
\begin{aligned}
& \lambda(t, T)=\frac{f(t, T)}{R(t, T)}=\frac{f(t, T)}{1-F(t, T)}=\frac{\frac{\beta(T)}{\eta(T)} \cdot\left(\frac{t}{\eta(T)}\right)^{\beta(T)-1} \cdot e^{-\left(\frac{t}{\eta(T)}\right)^{\beta(T)}}}{e^{-\left(\frac{t}{\eta(T)}\right)^{\beta(T)}}}= \\
& \frac{\beta(T)}{\eta(T)} \cdot \frac{t^{\beta(T)-1}}{\eta(T)^{\beta(T)-1}}=\frac{\beta(T) \cdot t^{\beta(T)-1}}{\eta(T)^{\beta(T)}}= \\
& \frac{\beta(T) \cdot t^{\beta(T)-1}}{a^{\beta(T)}} \cdot e^{-\left[\left(\frac{E_{a 1} \cdot\left(C(T) \cdot T_{T 1}+B(T) \cdot T\right)}{R \cdot T \cdot T_{T 1}}\right)+B(T) \cdot\left[e^{\left(\frac{D}{T}\right)}-e^{\left(\frac{D}{T_{T 1}}\right)}\right]\right]}, t>0
\end{aligned}
$$

where $F(t, T)$ is the distribution function of the Weibull distribution depending on the temperature $T$; $R(t, T)$ is the probability of a faultless state depending on the temperature $T ; f(t, T))$ is the probability density of Weibull distribution depending on the temperature $T$ and $t(\mathrm{~h})$ is the time to failure of electro-insulation system.

From the resulting Equation (24), the intensity of failures $\lambda(t, T)$ is variable depending on time $t(\mathrm{~h})$ and on the temperature $T(\mathrm{~K})$, which further characterizes the function parameter of shape of the Weibull distribution $\beta(T)$. These variables can be used for the bathtub curve (Figure 5), which characterizes the failure rates of the electrical insulating system at time $t$ and temperature $T$. 


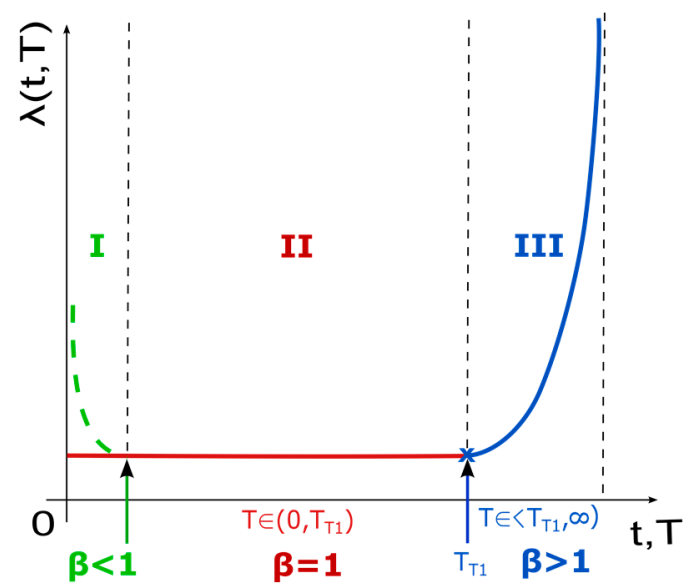

Figure 5. Bathtub curve.

The first period I was not considered in this case. Period II was characterized by a normal operational life where electrical insulation materials age very slowly. Only random failures, such as a lightning strike or overstressing, for determining the threshold values were considered. Period III indicated failures associated with the wear of electrical insulating materials, i.e., there was a significant aging process at that part of the curve.

It is, therefore, assumed that the passage between period II and III took place at the threshold of the effect of the degradation factor. This can be illustrated in Figure 6.

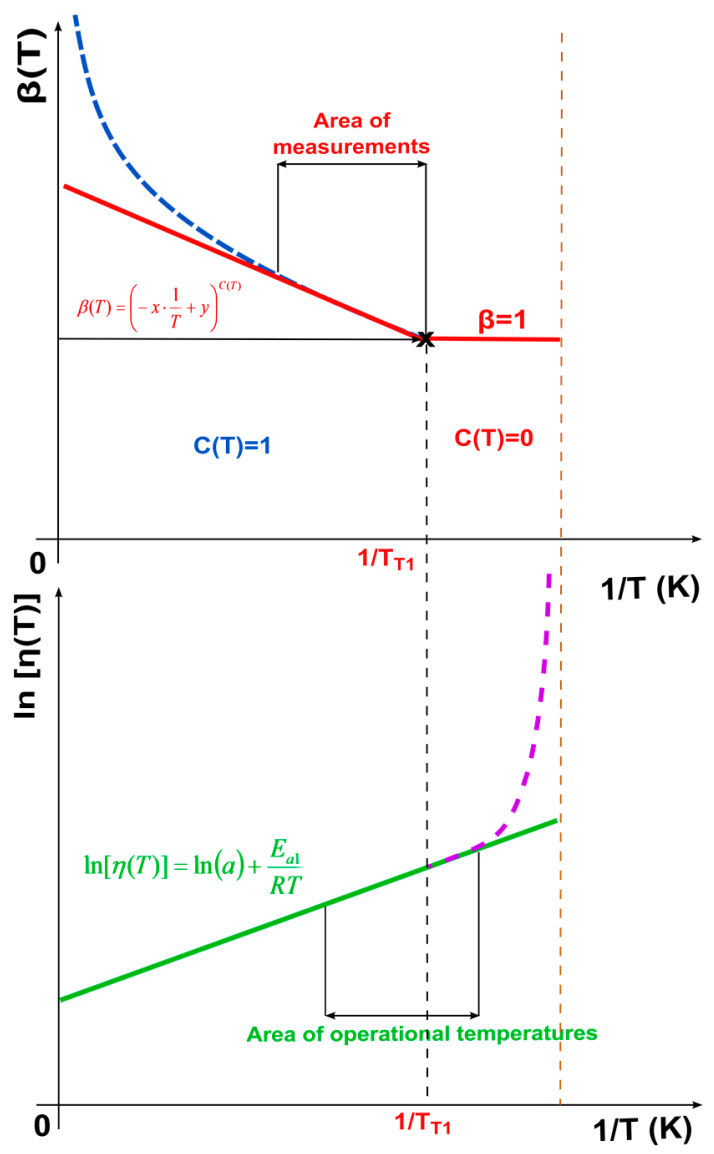

Figure 6. Determination of threshold value of the effect of degradation factor. 
The resultant of parameter $\beta(T)$ can be approximated by a linear function, which limits the impact of the degradation factor $T_{T 1}$ and takes the value equal to one in the experimental measurements and the normal operating temperature of the electrical equipment. There is an assumption only of random failures. This relationship is described by Equation (25).

$$
\beta(T)=\left(-x \cdot \frac{1}{T}+y\right)^{C(T)}
$$

where $x(\mathrm{~K})$ is the directive function of the parameter shape of the Weibull distribution; $\beta(T)$ depending on the temperature $T$ in operating temperature electrical insulation systems; $y$ is the absolute term and $C(T)$ is the function defining the threshold value of the effect of the degradation factor $T_{T 1}$ depending on the temperature $T$ (see Appendix A).

Expression of temperature $T$ and substituting the value of $\beta(T)=1$ (see previous reasoning (Equation (25)), the effect of the threshold value can be estimated from Equation (26).

$$
\hat{T}_{T 1}=\frac{x}{y-1}
$$

where $\hat{T}_{T 1}$ is the estimation of the threshold value of the effect of the degradation factor.

\section{Experimental Verification of Proposed Model}

The previously mentioned assumption was verified by a simple experimental measurement. Four sets of fifty samples of transformer board were subjected to thermal degradation at 160, 170 and $180^{\circ} \mathrm{C}$ for $240 \mathrm{~h}$, wherein the experimental measurements were performed in intervals of 120 and $240 \mathrm{~h}$, including measurement in initial conditions. Higher than recommended temperatures (standard EN 60085) were selected in order to observe a threshold in the aging data during the experiment. The dielectric strength was selected for model verification given that other aging parameters have a problematic end of life criteria. The experiment was carried out per standard IEC 60243-1 [52], when the breakdown occurred between 10 and $20 \mathrm{~s}$ due to increasing voltage at $400 \mathrm{~V} \cdot \mathrm{s}^{-1}$. A BDV test was carried out after $24 \mathrm{~h}$ of conditioning. The samples were naturally cooled down in the oven to ambient temperature and after this, the samples were placed in the climatic chamber for $24 \mathrm{~h}$. The ambient temperature and relative humidity $45 \%$ were set in the chamber. The samples were measured one-by-one. The procedure for establishing the probabilistic model using the thermal model with respect to the threshold value of the effect of the degradation factor for the experimental data is presented below.

\section{Procedure for Establishing the Probabilistic Model for Validation of Experimental Data}

Fifty samples in each set were used for the most accurate estimation and evaluation of the parameters of the Weibull distribution. The behavior of the dielectric strength in different degradation temperatures is shown in Figure 7. The graphs are interpreted as boxplots in software for statistical analysis called "Minitab 17" for better illustration. The values of time to failure were deduced for the resultant graphs, which were characterized by exceeding the selected criterion dielectric strength $\left(\mathrm{Ep}=12 \mathrm{kV} \cdot \mathrm{mm}^{-1}\right)$. The criterion set the resultant time scale but did not characterize the shape of the resistance curve against the degradation factor. This criterion was set as $85 \%$ of the arithmetic mean value of the dielectric strength of the transformer board at a supplied state and is presented as a horizontal red line in the boxplots. The time to failure was deduced as an intersection of individual values of dielectric strength with the criterion. 


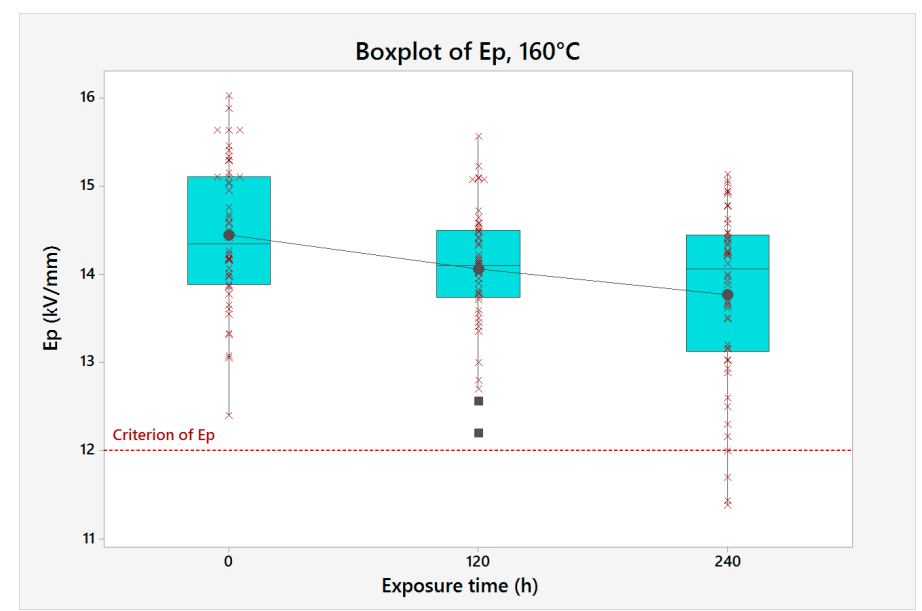

(a)

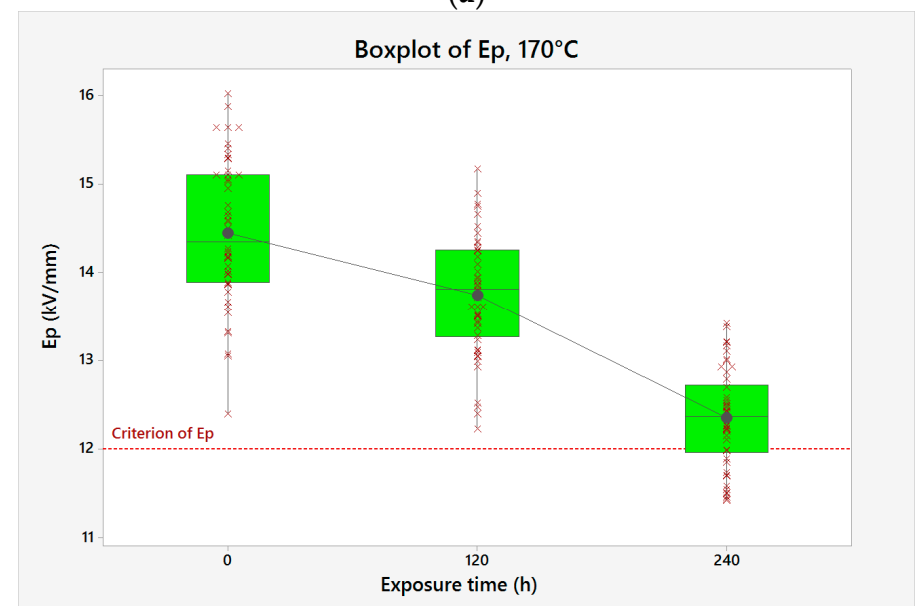

(b)

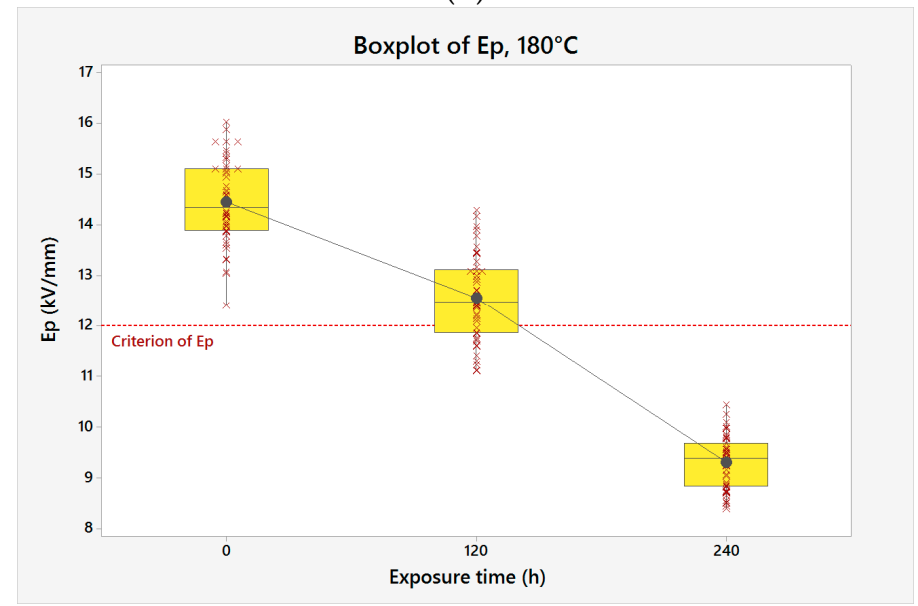

(c)

Figure 7. Dependence of dielectric strength (Ep) on degradation temperature: (a) $160{ }^{\circ} \mathrm{C}$; (b) $170{ }^{\circ} \mathrm{C}$; and (c) $180{ }^{\circ} \mathrm{C}$.

The maximum likelihood estimation (MLE) method was used for the most accurate estimation of the individual parameters of the Weibull distribution. The parameters of the Weibull distribution were estimated using a software Minitab 17 (Table 2). The estimation from the censored data was performed for the degradation temperature of $160{ }^{\circ} \mathrm{C}$, as the criterion was exceeded only in 25 cases out of 50 . The histograms of time to failure for the individual degradation temperatures are shown in Figure 8. 
Table 2. Estimation of individual parameters of the Weibull distribution for different temperature.

\begin{tabular}{cccccc}
\hline Temperature $\left({ }^{\circ} \mathbf{C}\right)$ & MLE $\hat{\boldsymbol{\beta}}$ & MLE $\hat{\boldsymbol{\eta}} \mathbf{( h )}$ & Confidence Interval & Median Me (h) & MTTF (h) \\
\hline 160 & 1.612 & 1184.643 & 0.95 & 944 & 1061.412 \\
170 & 4.181 & 351.152 & 0.95 & 310 & 327.013 \\
180 & 7.020 & 152.119 & 0.95 & 141 & 144.751 \\
\hline
\end{tabular}

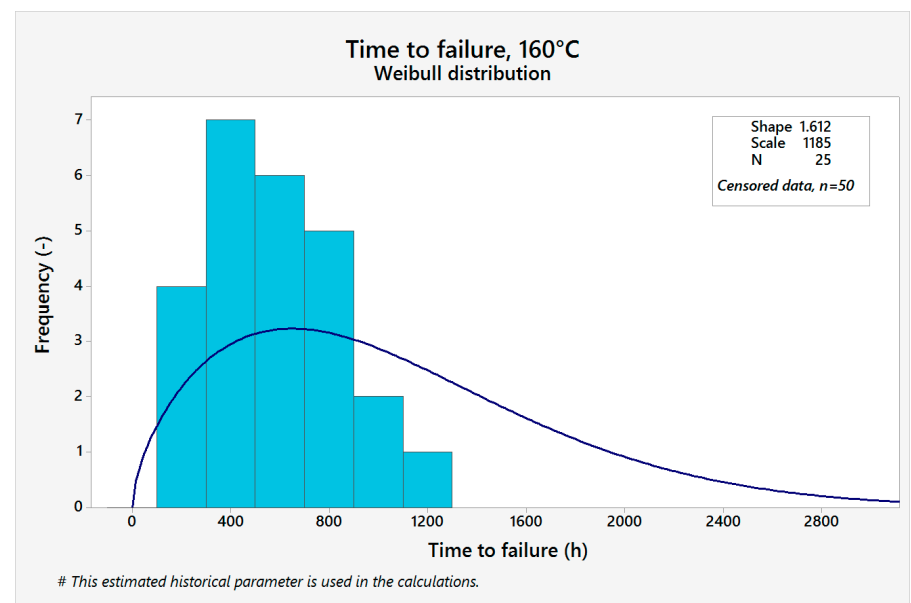

(a)

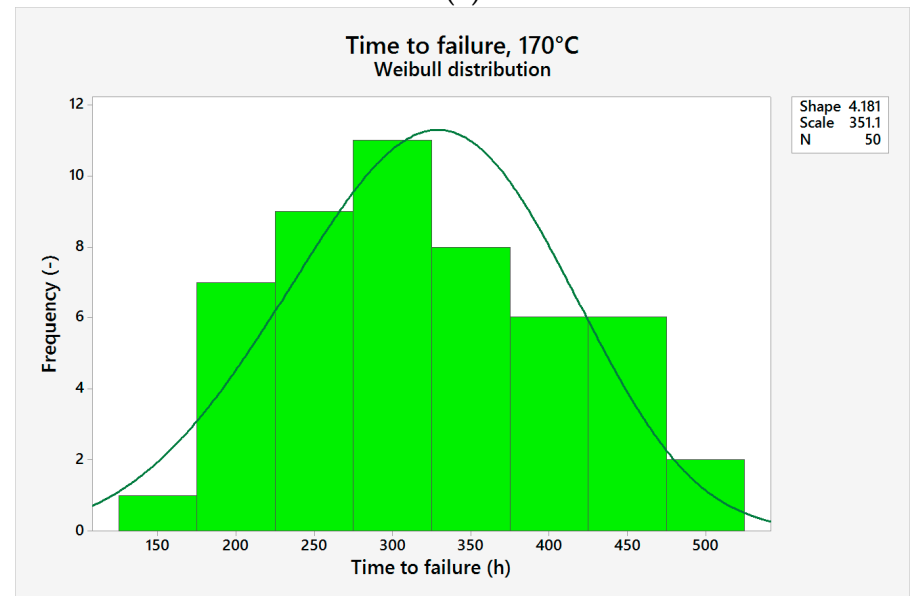

(b)

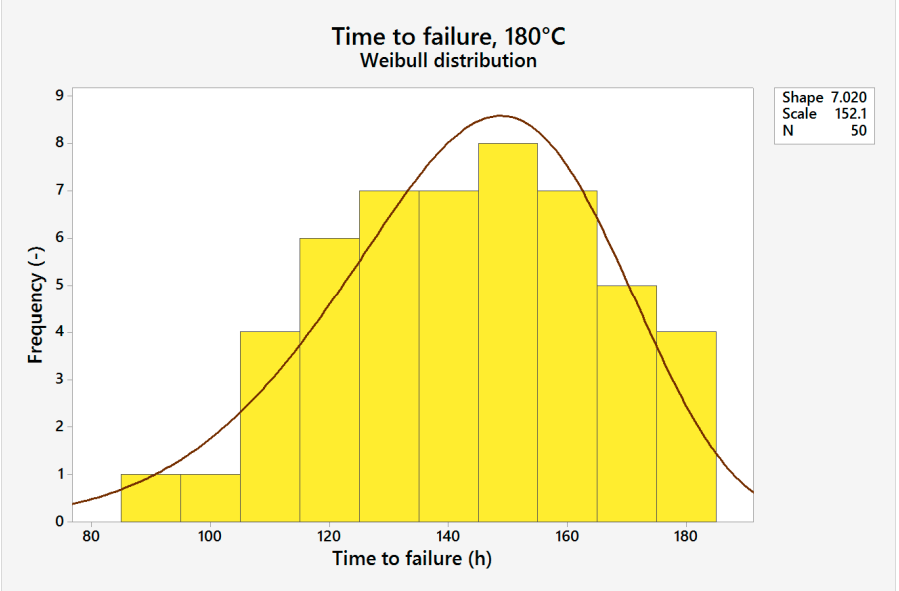

(c)

Figure 8. Histograms for time to failure of the transformer board at the selected temperatures: (a) $160{ }^{\circ} \mathrm{C}$; (b) $170{ }^{\circ} \mathrm{C}$; and (c) $180{ }^{\circ} \mathrm{C}$. 
There is a presumption in experimental measurement and normal temperatures that the resultant of parameter $\beta(T)$ can be approximated by a linear function which takes a value equal to one from the threshold value $T_{T 1}$ (Equation (26)). Similarly, a linear trend of parameter $\eta(T)$ in logarithmic scale can be assumed, i.e., the model assumes only Büssing's degradation mechanisms. This presumption is shown in Figure 5. Figure 5 also clearly shows that the second part of the model, which characterizes the different degradation factors, is neglected in the resultant probabilistic model. The equation of distribution functions of the Weibull distribution (Equation (22)) of the proposed probabilistic model can be rewritten as Equation (27) and equation density of the probability of the Weibull distribution (Equation (23)) can be rewritten as Equation (28).

$$
\begin{gathered}
F(t, T)=1-e^{-\left(\frac{t}{a} \cdot e^{\left.-\frac{E_{a 1}}{\mathrm{R} T}\right)^{\beta(T)}}\right.} \\
f(t, T)=\frac{\beta(T)}{a} \cdot e^{-\frac{E_{a 1}}{\mathrm{R} T}}\left(\frac{t}{a} \cdot e^{-\frac{E_{a 1}}{\mathrm{R} T}}\right)^{\beta(T)-1} \cdot e^{-\left(\frac{t}{a} \cdot e^{-\frac{E_{a 1}}{\mathrm{R} T}}\right)^{\beta(T)}}
\end{gathered}
$$

The course of estimated parameters $\hat{\beta}$ and $\hat{\eta}$-depending on the reciprocal temperature-was set based on estimations of the individual parameters of the Weibull distributions (Table 2) by using Equations (21) and (25). This course is shown in Figures 9 and 10 and was used to design the final probabilistic model.

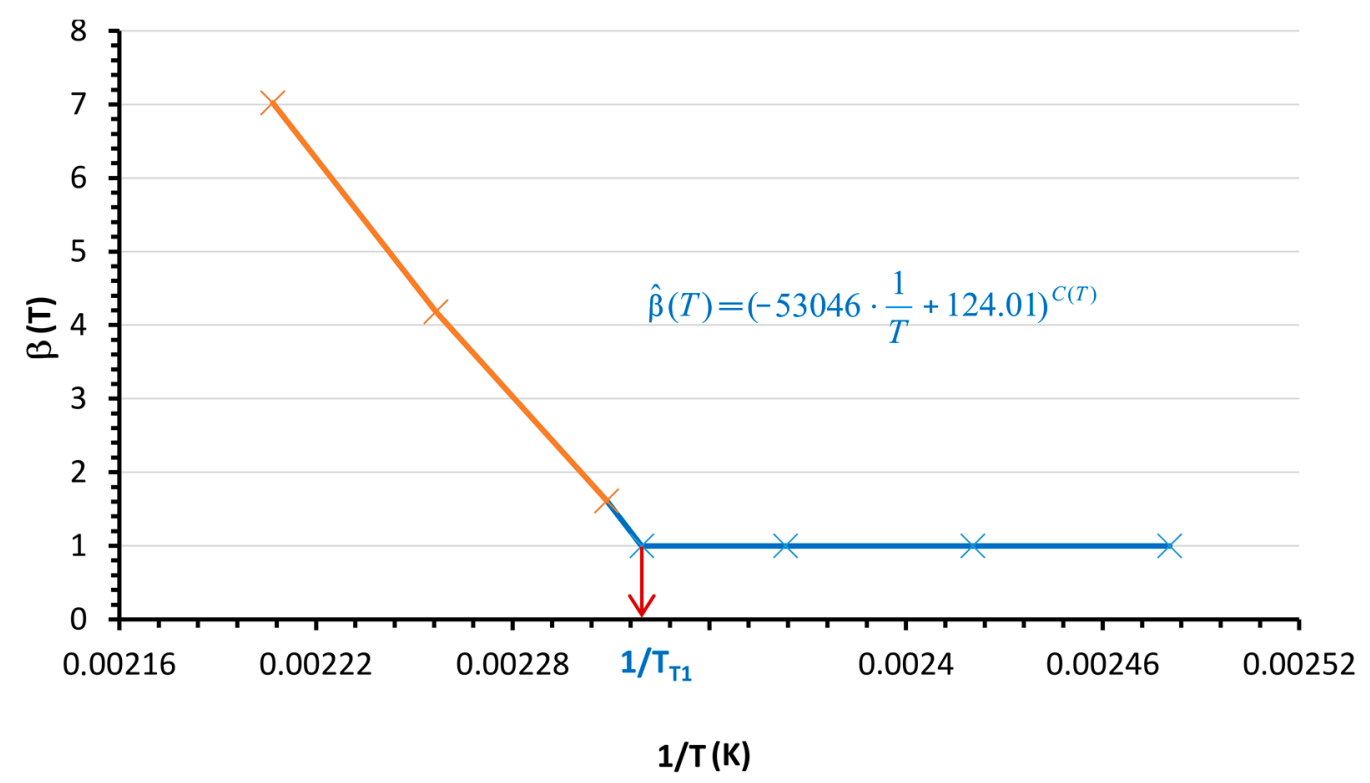

Figure 9. Parameter of the shape of the Weibull distribution depending on the reciprocal temperature. 


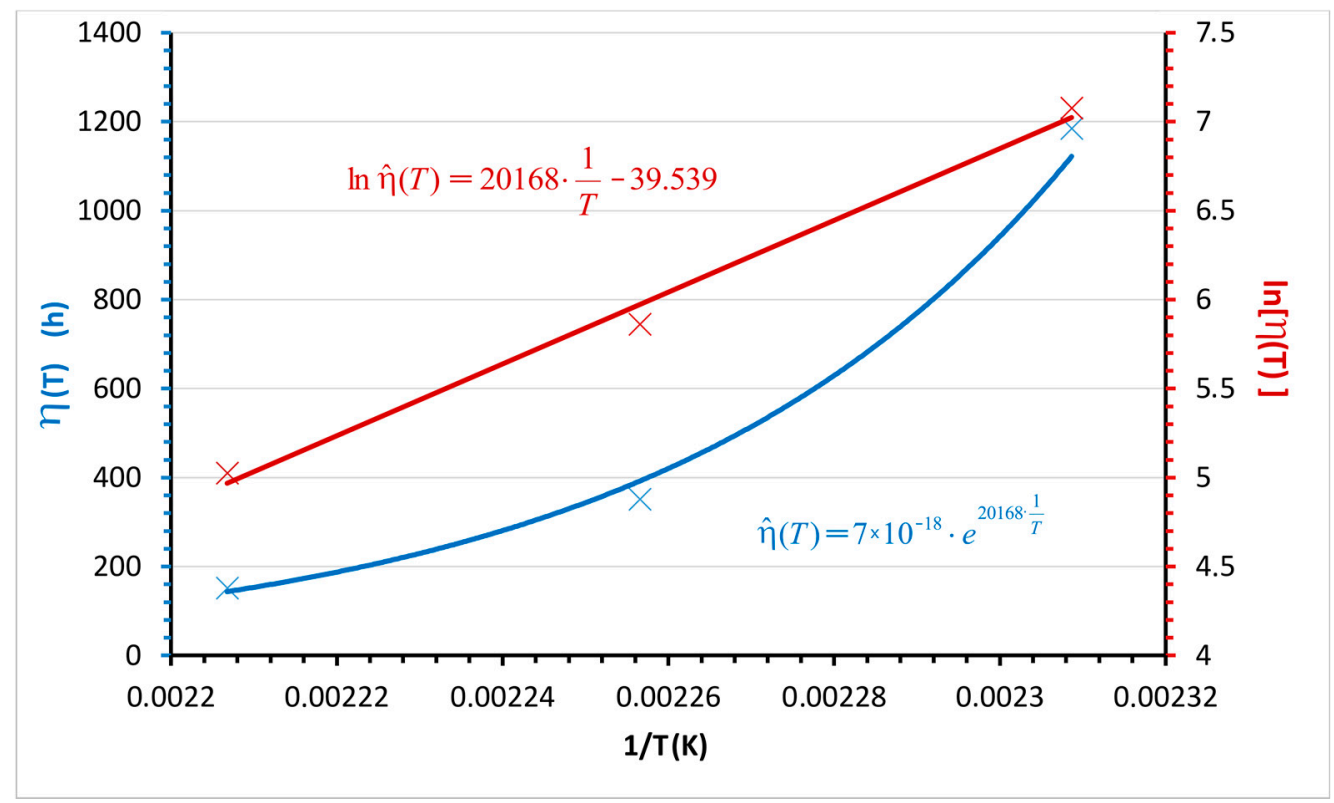

Figure 10. Parameter of the scale of the Weibull distribution depending on the reciprocal temperature.

Parameter $x(\mathrm{~K})$, which characterizes the directive of function $\beta(T)$ in normal process temperatures and absolution element $y$, were obtained by linear approximation of the function of the shape of the Weibull distribution depending on the reciprocal temperature. The final estimation of the threshold value $\hat{T}_{T 1}$ is calculated as per Equation (26) by substituting the mentioned parameters $x$ and $y$. This estimation is illustrated by Equation (29). The next calculated parameters and estimated functions are shown in Table 3.

$$
\stackrel{\mathrm{T}}{T 1}_{\mathrm{T}}=\frac{x}{y-1}=\frac{53046}{124.01-1}=431.23 \mathrm{~K}
$$

Table 3. Calculated parameters and estimated functions of probabilistic model.

\begin{tabular}{cc}
\hline Description & Function/Value of Parameter \\
\hline Course estimation of $\hat{\beta}(T)$ & $\hat{\beta}(T)=\left(-53046 \cdot \frac{1}{T}+124.01\right)$ \\
\hline Course estimation $\hat{\eta}(T)$ & $\hat{\eta}(T)=7 \times 10^{-18} \cdot e^{20168 \cdot \frac{1}{T}}$ \\
\hline Threshold value $\hat{T}_{T 1}(\mathrm{~K})$ & 431.23 \\
\hline Reciprocal value of pre-exponential factor $\alpha(\mathrm{h})$ & $7 \times 10^{-18}$ \\
\hline Activation energy $E_{a 1}\left(\mathrm{~J} \cdot \mathrm{mol}^{-1}\right)$ & $167,686.27$ \\
\hline $\begin{array}{c}\text { Function for defining the threshold value of } \\
\text { degradation factor } C(T)\end{array}$ & $C(T)=\frac{1}{2 \pi} \cdot\left\{\pi+2 \operatorname{arctg}\left[\left(\lim _{s \rightarrow \infty} s\right) \cdot(T-431.23)\right]\right\}$ \\
\hline
\end{tabular}

The final model can be written as Equations (30) and (31) by substituting the universal gas constant $\mathrm{R}$ and parameters from Table 3 into Equation (27).

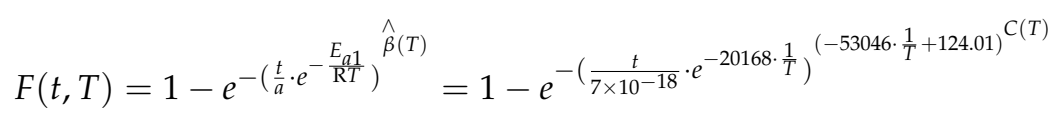




$$
\begin{aligned}
& f(t, T)=\frac{\hat{\beta}(T)}{a} \cdot e^{-\frac{E_{a 1}}{\mathrm{R} T}}\left(\frac{t}{a} \cdot e^{-\frac{E_{a 1}}{\mathrm{R} T}}\right)^{\hat{\beta}(T)-1} \cdot e^{-\left(\frac{t}{a} \cdot e^{-\frac{E_{a 1}}{\mathrm{R} T}}\right)^{\hat{\beta}(T)}}= \\
& \frac{\left(-53046 \cdot \frac{1}{T}+124.01\right)^{C(T)}}{7 \times 10^{-18}} \cdot e^{-20168 \cdot \frac{1}{T}}
\end{aligned}
$$

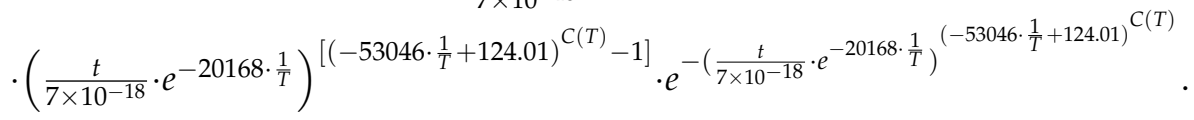

If Equations (30) and (31) are known, the courses of the distribution function and density of probability can be constructed as $3 \mathrm{D}$ plots depending on the temperature. These dependences are shown in Figures 11 and 12.

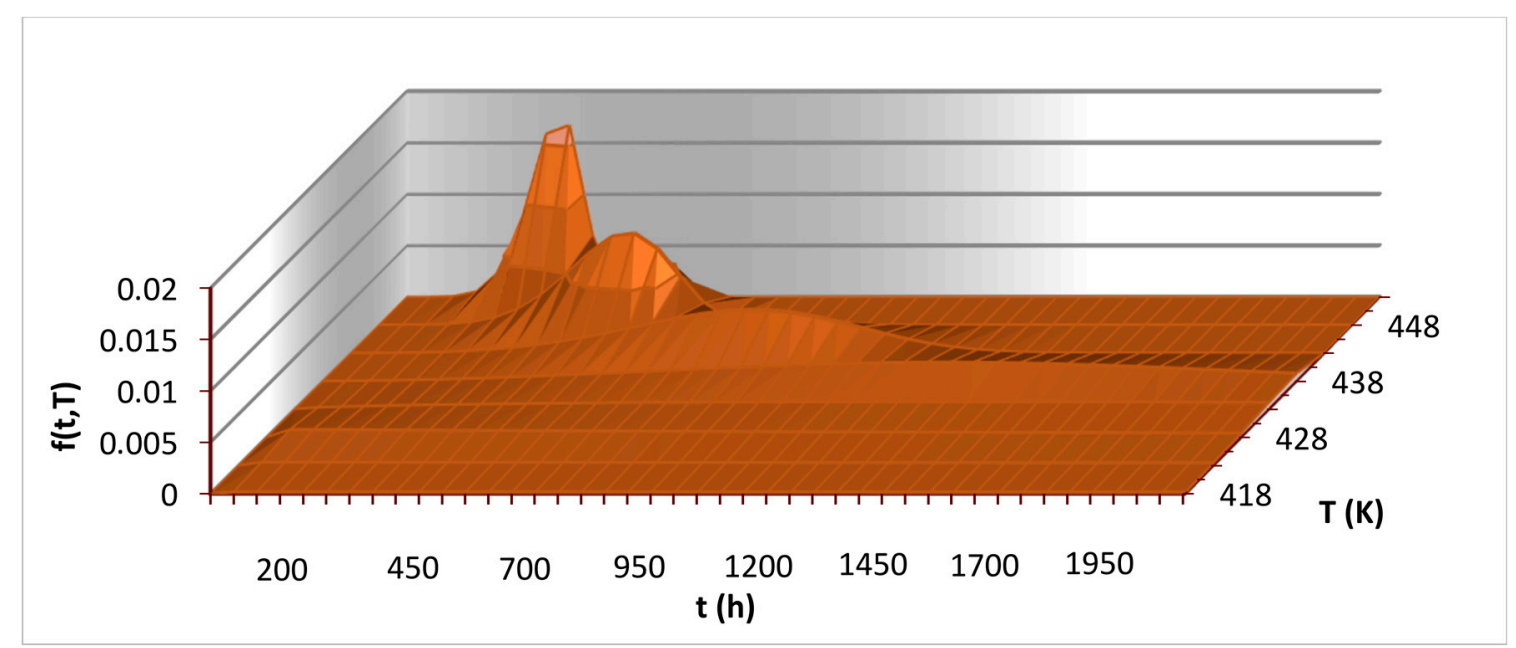

Figure 11. 3D plot of estimations of the density of probability of the Weibull distribution depending on temperature for the proposed probabilistic model.

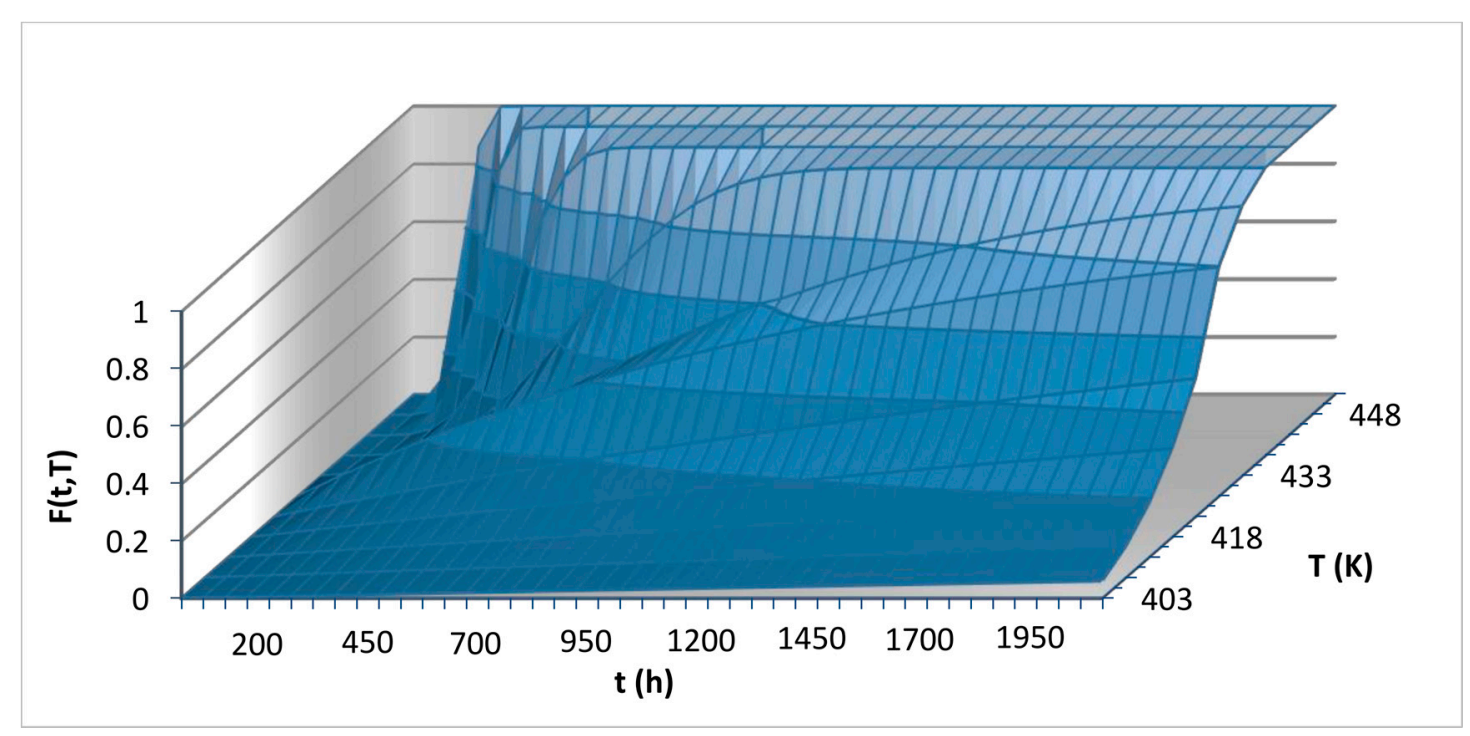

Figure 12. 3D plot of estimations of the distribution functions of the Weibull distribution depending on temperature for the proposed probabilistic model.

Three dimensional plots of estimation of the distribution function can be used as the resultant probabilistic model with the usage of thermal aging. It is clearly visible that the distribution function and density of probability of the Weibull distribution changed due to the variable value of the degradation factor; in this case, temperature. Figure 11 shows that the density of probability had 
an exponential shape distribution up to $T_{T 1}$; after this point, the density of probability looked like a Weibull distribution.

Proposed theory of the determination of threshold value $T_{T 1}$ can be confirmed by theory [53]. In this case, the dissolved gasses in transformer oils in different transformers were studied for three years. From reason is clearly visible that the estimations of parameter $\beta$ were close to 1 , it means that transformer oil did not age and the operational temperature was below the value of degradation factor $T_{T 1}$.

The next publication [54] shows that the proposed methodology is applicable for electrical aging as well. In this case, the transformer windings were placed to transformer oil and time to breakdown were measured at different voltages levels. From the results, it is clearly visible that the value of parameter $\beta$ of Weibull distribution decreases with the intensity of electric field until to the 1 . The projection of intensity of electric field and parameter $\beta$ can be used as the threshold value of degradation factor $T_{T 1}$.

\section{Conclusions}

The proposed model of thermal aging with respect to the threshold value of the degradation factor is based on the traditional model of thermal aging. This model tries to include the listed thresholds to calculations through mathematical-physical presumptions. The model is based on presumptions of the infinity of limit states and when these are exceeded, different degradation mechanisms occur. One main advantage is that this model includes physical principles and corresponds better to the real conditions of an insulation system. The disadvantage is that the relatively difficult experimental determination of the threshold value $T_{T 1}$. It also corresponded to the inability to determine the synergy constant $D$ before the $T_{T 1}$ by experimental measurement.

The proposed model can provide information on the probability of failure during the variable degradation factor. The next advantage is that this model can be used for threshold value $T_{T 1}$ determination by the linear approximation of the parameter of shape of function $\beta(T)$ of the Weibull distribution depending on temperature $T$. It was not necessary to achieve this value by experimental measurement. However, this model only considers one degradation factor, and many experimental samples must be used for its estimation.

This model was experimentally verified by the measurement of dielectric strength on four sets of transformer board. Implementation of the thermal aging model to the Weibull distribution eliminated the disadvantages of the unpredictability of probability of times to failure for the variable intensity of the effect of the degradation factor and was presented in the experimental part of this paper. As seen, an effort has been done to better estimate the service life of an insulation system. Since real degradation is far from the stress applied during aging tests, this model—despite being difficult in application-could save costs when one considers the over-dimensioning of insulation systems in energy networks.

Acknowledgments: This work has been supported by the Ministry of Education, Youth and Sports of the Czech Republic under the RICE-New Technologies and Concepts for Smart Industrial Systems, project No. LO1607 and by the Student Grant Agency of the West Bohemia University in Pilsen, grant No. SGS-2015-020 “Technological and Material Systems in Electrical Engineering".

Author Contributions: Jakub Souček and Pavel Trnka conceived and designed the experiments; Jaroslav Hornak and Jakub Souček performed the experiments; Jakub Souček and Pavel Trnka analyzed the data; and Jaroslav Hornak, Jakub Souček and Pavel Trnka wrote the paper.

Conflicts of Interest: The authors declare no conflict of interest. 


\section{Appendix}

\section{Appendix A.1 List of Variables and Constants}

$\beta$
$\eta$
$\Gamma(z)$
$\tau(\mathrm{h})$
$A(\mathrm{~h}), B\left(\mathrm{~K}^{-1}\right)$
$k\left(\mathrm{~s}^{-1}\right)$
$T(\mathrm{~K})$
$A^{*}\left(\mathrm{~s}^{-1}\right)$
$E_{a}\left(\mathrm{~J} \cdot \mathrm{mol}^{-1}\right)$
$\mathrm{R}\left(\mathrm{J} \cdot \mathrm{K}^{-1} \cdot \mathrm{mol}^{-1}\right)$
$a(\mathrm{~h})$
$E\left(\mathrm{kV} \cdot \mathrm{mm}^{-1}\right)$
$k\left(\mathrm{kV} \cdot \mathrm{mm}^{-} \mathrm{h}\right), N$
$b\left(\mathrm{kV} \cdot \mathrm{mm}^{*}, c^{*}(\mathrm{~h})\right.$
$\tau_{0}(\mathrm{~h})$
$E_{0}\left(\mathrm{kV} \cdot \mathrm{mm}^{-1}\right)$
$X_{1}\left(\mathrm{kV}-1 \cdot \mathrm{mm}^{-1}, X_{2}\left(\mathrm{kV} \cdot \mathrm{mm}^{-1} \cdot \mathrm{h}\right)\right.$
$E_{a n}\left(\mathrm{~J} \cdot \mathrm{mol}^{-1}\right)$
$T_{T n}(\mathrm{~K})$
$\tau_{i}(\mathrm{~h})$
$K_{i}$
$\tau_{M}(\mathrm{~h})$
$D(\mathrm{~K})$
$T_{T 1}(\mathrm{~K})$
$K_{M}$

shape parameter of Weibull distribution

scale parameter of Weibull distribution

Gamma function

lifetime

material constants

reaction rate

absolute temperature

pre-exponential factor or frequency factor

activation energy of thermal process

universal gas constant, which has the value $8.3144598 \mathrm{~J} \cdot \mathrm{K}^{-1} \cdot \mathrm{mol}^{-1}$

reciprocal value of the pre-exponential factor $A^{*}$

intensity of the electric field

material constants

material constants

lifetime of the insulation system for threshold value

threshold value of the intensity of the electric field

material constants

activation energies of thermal processes which define partial degradation

mechanisms and characterize aging electrical insulating system at intervals of extreme temperatures $T_{T 1}$ up to $T_{T n}$

extreme of the temperature intervals that define partial degradation mechanisms lifetime of the insulation system in the temperature range $T \in\left\langle T_{T i}, T_{T(i-1)}\right)$

partial correction parameter of new model for preservation of condition

$K_{i}=\frac{\tau_{T(i-1)}\left(T_{T(i-1)}\right)}{\tau_{T i}\left(T_{T(i-1)}\right)}$

modified model of thermal aging in range of temperature $T \in\left(0, T_{T 1}\right)$

material constant, which is characterized by synergistic effect of partial

degradation mechanisms

threshold value of the degradation factor of the new model

correction parameter of modified model for preservation of condition

$\tau_{1}\left(T_{T 1}\right)=\tau_{M}\left(T_{T 1}\right)$

functions defining the threshold value of the effect of the degradation factor $T_{T 1}$

$B(T)$ and $C(T)$

$\beta(T)$

depending on the temperature $T$, for which you apply $B(T)=0 ; C(T)=1$ for $T \in$ $\left\langle T_{T 1}, \infty\right)$ and $B\left(T=0\right.$ for $T \in\left(0, T_{T 1}\right)$.

function of the shape parameter of Weibull distribution depending on the temperature $T(\mathrm{~K})$

$\eta(T)(\mathrm{h})$

$t(\mathrm{~h})$

function of the scale parameter of Weibull distribution depending on the

temperature $T(\mathrm{~K})$

time to failure of insulation system

distribution function which depend on time to failure $t$ and temperature $T(\mathrm{~K})$ probability density which depend on time to failure $t(\mathrm{~h})$ and temperature $T(\mathrm{~K})$

intensity of failures which depend on time to failure $t(\mathrm{~h})$ and temperature $T(\mathrm{~K})$

$\lambda(t, T)$

$\hat{T}_{T 1}(\mathrm{~K})$

estimation of threshold value of the effect of degradation factor

Ep $\left(\mathrm{kV} \cdot \mathrm{mm}^{-1}\right)$

dielectric strength 
Appendix A.2 Functions $B(T)$ a $C(T)$

The function $B(T)$ is characterized as the cyclometric function -arctg offset by $1 / 2$ on the $B$ axis, multiplied by the constant $1 / \pi$ and shifted by the $T_{T 1}$ temperature multiplied by the infinity constant s. This function is subsequently described by Equation (A1) and is shown in Figure A1.

$$
\begin{gathered}
B(T)=\frac{1}{\pi} \cdot \operatorname{arctg}\left[\left(\lim _{s \rightarrow \infty} s\right) \cdot\left(T_{T 1}-T\right)\right]+\frac{1}{2}= \\
\frac{1}{2 \pi} \cdot\left\{\pi+2 \operatorname{arctg}\left[\left(\lim _{s \rightarrow \infty} s\right) \cdot\left(T_{T 1}-T\right)\right]\right\},
\end{gathered}
$$

where $s$ is the infinity constant; $T_{T 1}$ is the threshold value of the effect of the degradation mechanism limiting the validity of the proposed model. The constant $s$ has been introduced to maintain the stepwise shape of the $B(T)$ function.

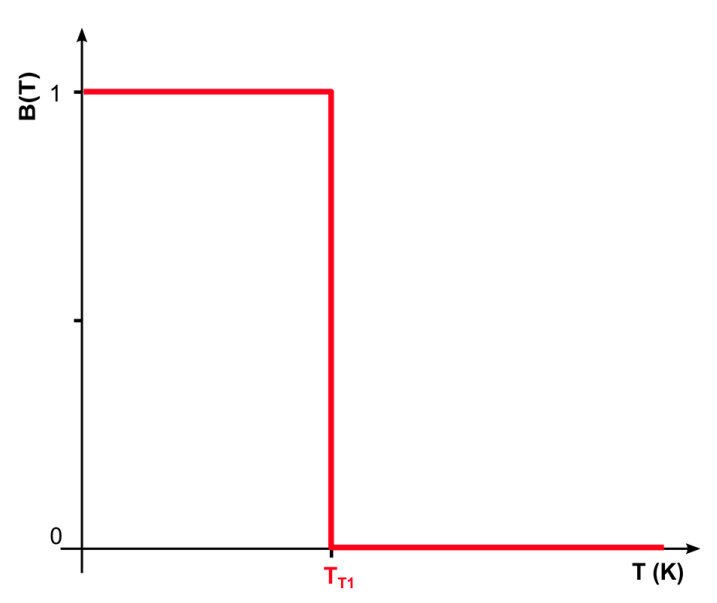

Figure A1. Function $B(T)$.

Like $B(T)$, function $C(T)$ is defined. It has the opposite course as function $B(T)$ and is based on the cyclometric function $\operatorname{arctg}$. The temperature difference $\left(T_{T 1}-T\right)$ therefore takes the opposite sign, i.e., $\left(T-T_{T 1}\right)$. The $C(T)$ function is subsequently described by Equation (A2) and is shown in Figure A2.

$$
\begin{gathered}
C(T)=\frac{1}{\pi} \cdot \operatorname{arctg}\left[\left(\lim _{s \rightarrow \infty} s\right) \cdot\left(T-T_{T 1}\right)\right]+\frac{1}{2}= \\
\frac{1}{2 \pi} \cdot\left\{\pi+2 \operatorname{arctg}\left[\left(\lim _{s \rightarrow \infty} s\right) \cdot\left(T-T_{T 1}\right)\right]\right\} .
\end{gathered}
$$

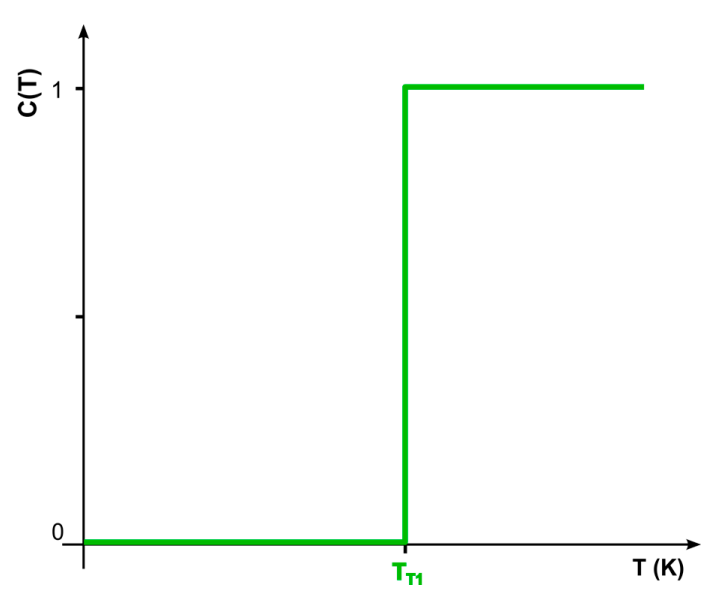

Figure A2. Function $C(T)$. 
Appendix A.3 The D Constant Defining the Synergistic Effect of Partial Degradation Mechanisms

Due to the high time-consuming experiments, this constant cannot be experimentally determined. For this reason, this constant will be estimated. Determining this constant is one future direction of research.

Constant $D$ is estimated by introducing an empirical rule. This rule assumes that when the temperature drops by $T_{K}(\mathrm{~K})$ from the threshold value $T_{T 1}$, the lifetime of the insulation system will increase $M_{K}$ times compared to the life of the original thermal aging model $\tau_{1}$. This assumption describes Equation (A3) and is shown in Figure A3.

$$
M_{K} \cdot \tau_{1}\left(T_{T 1}-T_{K}\right)=\tau_{M}\left(T_{T 1}-T_{K}\right)
$$

where $\tau_{1}(\mathrm{~h})$ is the lifetime of the electrical insulation system for $T \in\left(T_{T 1}, \infty\right) ; \tau_{M}(\mathrm{~h})$ is the lifetime of the electrical insulation system for $T \in\left(0, T_{T 1}\right) ; T_{T 1}(\mathrm{~K})$ is the threshold value of the influence of the degradation factor; $M_{K}$ is the multiplicative constant; and $T_{K}(K)$ is the absolute value of the temperature drop from $T_{T 1}$.

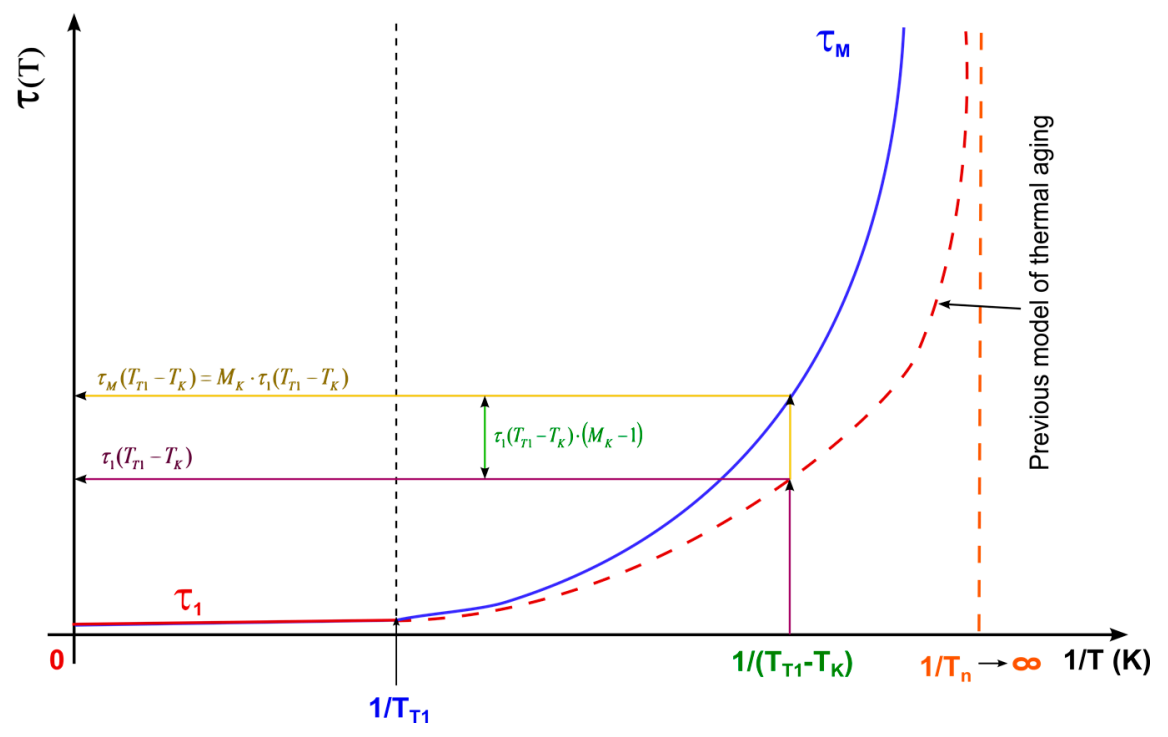

Figure A3. A graphical representation of the constant $D$, estimating the synergistic effect of the partial degradation mechanisms.

Subsequently, the equation for estimating the constant $\hat{D}$ is obtained by Equation (A4).

$$
\begin{aligned}
& M_{K} \cdot a \cdot e^{\frac{E_{a 1}}{\mathrm{R}\left(T_{T 1}-T_{K}\right)}}=a \cdot e^{\left[\left(\frac{E_{a 1}}{\mathrm{R} T}\right)-e^{\left(\frac{\hat{D}}{T_{T 1}}\right)}\right]} e^{e^{\left(\frac{\hat{D}}{T}\right)}} \\
& M_{K} \cdot e^{\frac{E_{a 1}}{R\left(T_{T 1}-T_{K}\right)}} \cdot e^{-\left(\frac{E_{a 1}}{R T_{T 1}}\right)} \cdot e^{\left(\frac{\hat{D}}{T_{T 1}}\right)} \cdot e^{-e^{\left(\frac{\hat{D}}{\left(T_{T 1}-T_{K}\right)}\right)}}=1
\end{aligned}
$$

Equation (A4) also derives the final form of the equation estimating the constant $\hat{D}$ by defining the synergic effect of partial degradation mechanisms (Equation (5)). By solving the equations, the resulting estimation of the constant $\hat{D}$ is obtained.

A more detailed derivation of Equation (A5) is described by Equations (A6)-(A12).

$$
\sqrt[T_{T 1}]{e^{\hat{D}}}-\sqrt[\left(T_{T 1}-T_{K}\right)]{e^{\hat{D}}}+\ln \left(M_{K} \cdot e^{\left[\frac{E_{a 1} \cdot T_{K}}{R \cdot T_{T 1} \cdot\left(T_{T 1}-T_{K}\right)}\right]}\right)=0
$$


Appendix A.4 Deriving the Resulting Equation for Estimating the Constant D Defining the Synergistic Effect of the Partial Degradation Mechanisms

The first part of the model for $T \in\left\langle T_{T 1}, \infty\right)$ :

$$
\tau(T)=\tau_{1}=K_{1} \cdot a \cdot \tau_{T 1}=K_{1} \cdot a \cdot e^{\frac{E_{a 1}}{\mathrm{RT}}}=a \cdot e^{\frac{E_{a 1}}{\mathrm{RT}}}
$$

The second part of the model for $T \in\left(0, T_{T 1}\right)$ :

$$
\tau_{M}(T)=K_{M} \cdot a \cdot \tau_{T M}=K_{M} \cdot a \cdot e^{e^{\left(\frac{D}{T}\right)}}=a \cdot e^{\left[\left(\frac{E_{a 1}}{R T T 1}\right)-e^{\left(\frac{D}{T} T 1\right.}\right)} e^{e^{\left(\frac{D}{T}\right)}}
$$

Introduction of an empirical rule:

$$
M_{K} \cdot \tau_{1}\left(T_{T 1}-T_{K}\right)=\tau_{M}\left(T_{T 1}-T_{K}\right)
$$

Apply Equations (A6) and (A7) to Equation (A8):

$$
\begin{gathered}
M_{K} \cdot a \cdot e^{\frac{E_{a 1}}{R\left(T_{T 1}-T_{K}\right)}}=a \cdot e^{\left[\left(\frac{E_{a 1}}{R T_{T 1}}\right)-e^{\left(\frac{\hat{D}}{T_{T 1}}\right)}\right]} e^{e^{\left(\frac{\hat{D}}{T}\right)}} \\
M_{K} \cdot e^{\frac{E_{a 1}}{R\left(T_{T 1}-T_{K}\right)}} \cdot e^{-\left(\frac{E_{a 1}}{R T_{T 1}}\right)} \cdot e^{\left(\frac{\hat{D}}{e_{T 1}}\right)} \cdot e^{-e^{\left(\frac{\hat{D}}{\left(T_{T 1}-T_{K}\right)}\right)}}=1
\end{gathered}
$$

Introduction of substitution $S_{K}$ :

$$
\begin{aligned}
& S_{K}=M_{K} \cdot e^{\frac{E_{a 1}}{\mathrm{R}\left(T_{T 1}-T_{K}\right)}} \cdot e^{-\left(\frac{E_{a 1}}{\mathrm{R} T_{T 1}}\right)}=M_{K} \cdot e^{\left[\frac{T_{T 1} \cdot E_{a 1}}{\mathrm{R}\left(T_{T 1}-T_{K}\right) \cdot T_{T 1}}-\frac{\left(T_{T 1}-T_{K}\right) \cdot E_{a 1}}{\mathrm{R}\left(T_{T 1}-T_{K}\right) \cdot T_{T 1}}\right]}= \\
& M_{K} \cdot e^{\left[\frac{E_{a 1} \cdot T_{K}}{\mathrm{R} \cdot T_{T 1} \cdot\left(T_{T 1}-T_{K}\right)}\right]}
\end{aligned}
$$

Equation solution (A10) with substitution Equation (A11):

$$
\begin{aligned}
& S_{K} \cdot e^{e^{\left(\frac{\hat{D}}{T_{T 1}}\right)}} \cdot e^{-e^{\left(\frac{\hat{D}}{\left(T_{T 1}-T_{K}\right)}\right)}}=1 \\
& e^{\left(\frac{\hat{D}}{T_{T 1}}\right)}-e^{\left(\frac{\hat{D}}{\left(T_{T 1}-T_{K}\right)}\right)}+\ln \left(S_{K}\right)=0 \\
& \sqrt[T_{T 1}]{e^{\hat{D}}}-\sqrt[\left(T_{T 1}-T_{K}\right)]{e^{\hat{D}}}+\ln \left(S_{K}\right)=0
\end{aligned}
$$

Undo applied substitution $S_{K}$ (A11) and the resulting form of the equation for calculating the estimation of the constant $\hat{D}$ by defining the synergistic effect of the partial degradation mechanisms:

$$
\sqrt[T_{T 1}]{e^{\hat{D}}}-\sqrt[\left(T_{T 1}-T_{K}\right)]{e^{\hat{D}}}+\ln \left(M_{K} \cdot e^{\left[\frac{E_{a 1} \cdot T_{K}}{\bar{R} \cdot T_{T 1} \cdot\left(T_{T 1}-T_{K}\right)}\right]}\right)=0
$$

\section{References}

1. Feilat, E.A.; Grzybowski, S.; Knight, P. Accelerated aging of high voltage encapsulated transformers for electronics applications. In Proceedings of the 6th International Conference on Properties and Applications of Dielectric Materials, Xi'an, China, 21-26 June 2000; Volume 1, pp. 209-212. [CrossRef]

2. Lundgaard, L.E.; Hansen, W.; Linhjell, D.; Painter, T.J. Aging of oil-impregnated paper in power transformers. IEEE Trans. Power Deliv. 2004, 19, 230-239. [CrossRef]

3. Montanari, G.C.; Simoni, L. Aging phenomenology and modeling. IEEE Trans. Electr. Insul. 1993, 28, 755-776. [CrossRef] 
4. Chinh, D.; Parpal, J.L.; Crine, J.P. Electrical aging of extruded dielectric cables: Review of existing theories and data. IEEE Trans. Dielectr. Electr. Insul. 1996, 3, 237-247. [CrossRef]

5. Augood, D.R. Dielectric aging-Overview \& comment. In Proceedings of the 1978 IEEE International Conference on Electrical Insulation, Philadelphia, PA, USA, 7-9 June 1978; pp. 17-21. [CrossRef]

6. Whitman, L.C.; Doigan, P. Calculation of life characteristics of insulation. Trans. Am. Inst. Electr. Eng. Part I Commun. Electron. 1954, 73, 193-198. [CrossRef]

7. Moonesan, M.S.; Jayaram, S.; Cherney, E.; Omranipour, R.; Haq, S.U. Analysis of times-to-failure of various turn insulations of form-wound coils under PWM voltage waveform. In Proceedings of the Electrical Insulation Conference (EIC), Ottawa, ON, Canada, 2-5 June 2013; pp. 187-190. [CrossRef]

8. Stone, G.C.; Lawless, J.F. The Application of Weibull Statistics to Insulation Aging Tests. IEEE Trans. Electr. Insul. 1979, EI-14, 233-239. [CrossRef]

9. IEEE. Guide for the Statistical Analysis of Electrical Insulation Voltage Endurance Data; ANSI/IEEE Std 930-1987; The Institute of Electrical and Electronics Engineers, Inc.: New York City, NY, USA, 1987; pp. 1-36. [CrossRef]

10. Wichmann, A.; Gruenewald, P. Influence of dielectric stress concentration on voltage endurance of epoxy-mica generator insulation. In Proceedings of the 1976 IEEE International Conference on Electrical Insulation, Montreal, QC, Canada, 14-16 June 1976; pp. 88-92. [CrossRef]

11. Meyer, H. Voltage endurance of electrical insulation. In Proceedings of the 1967 Seventh Electrical Insulation Conference, Chicago, IL, USA, 15-19 October 1967; pp. 268-271. [CrossRef]

12. Liu, X.; Zhang, T.; Bai, Y.; Ding, X. Wang, Y. Effects of accelerated repetitive impulse voltage aging on performance of model stator insulation of wind turbine generator. IEEE Trans. Dielectr. Electr. Insul. 2014, 21, 1506-1515. [CrossRef]

13. Dakin, T.W.; Studniarz, S.A. The Voltage Endurance of Cast Epoxy Resins. In Proceedings of the IEEE International Symposium on Electrical Insulation, Philadelphia, PA, USA, 12-14 June 1978; pp. 216-221. [CrossRef]

14. Ruijin, L.; Chao, T.; Lijun, Y.; Huanchao, C. Thermal aging studies on cellulose insulation paper of power transformer using AFM. In Proceedings of the 2006 IEEE 8th International Conference on Properties \& Applications of Dielectric Materials, Bali, Indonesia, 26-30 June 2006; pp. 722-725. [CrossRef]

15. Han, S.; Li, Q.; Li, C.; Yan, J. Electrical and mechanical properties of the oil-paper insulation under stress of the hot spot temperature. IEEE Trans. Dielectr. Electr. Insul. 2014, 21, 179-185. [CrossRef]

16. Jandial, A.P.; Spade, R.L. A study of the effects of long term exposure to rated operating temperature upon electrical properties of lead wire insulations. In Proceedings of the 1967 Seventh Electrical Insulation Conference, Chicago, IL, USA, 15-19 October 1967; pp. 226-231. [CrossRef]

17. Pradhan, A.K.; Chatterjee, B.; Chakravorti, S. Effect of temperature on frequency dependent dielectric parameters of oil-paper insulation under non-sinusoidal excitation. IEEE Trans. Dielectr. Electr. Insul. 2014, 21, 653-661. [CrossRef]

18. Heyda, P.G. Theoretical aspects of mechanical stresses in a paper-lapped cable insulation. Proc. Inst. Electr. Eng. 1967, 114, 1507-1510. [CrossRef]

19. Wilk, D.J. Radiation effects on epoxy insulation system versus silicone system for rotating equipment applications. In Proceedings of the 1971 EIC 10th Electrical Insulation Conference, Chicago, IL, USA, 20-23 September 1971; pp. 202-204. [CrossRef]

20. Melcher, J.; Deben, Y.; Arlt, G. Dielectric effects of moisture in polyimide. IEEE Trans. Electr. Insul. 1989, 24, 31-38. [CrossRef]

21. Stone, G. Electrical Insulation for Rotating Machnies; Wiley: Piscataway, NJ, USA, 2004; ISBN 0-471-44506-1.

22. Mentlik, V.; Hornak, J.; Trnka, P.; Harvanek, L. Effects of individual chemical cleaning detergents on conditions of winding surface. In Proceedings of the 2016 IEEE International on Dielectrics, Montpellier, France, 3-7 July 2016; pp. 768-771. [CrossRef]

23. Trnka, P.; Soucek, J.; Hornak, J.; Totzauer, P. EIS aging estimation and threshold values. In Proceedings of the 2016 IEEE International Conference on High Voltage Engineering and Application, Chengdu, China, 19-22 September 2016; pp. 1-4. [CrossRef]

24. Montanari, G.C.; Cacciari, M. A probabilistic life model for insulating materials showing electrical thresholds. IEEE Trans. Electr. Insul. 1989, 24, 127-134. [CrossRef] 
25. Souček, J.; Trnka, P. A new statistical-physical model to the description of aging of electroinsulating systems. In Proceedings of the 2014 15th International Scientific Conference on Electric Power Engineering, Brno, Czech Republic, 12-14 May 2014; pp. 463-466. [CrossRef]

26. Crine, J.-P.; Parpal, J.-L.; Dang, C. A new approach to the electric aging of dielectrics. In Proceedings of the Conference on Electrical Insulation and Dielectric Phenomena, Leesburg, VA, USA, 29 October-2 November 1989; pp. 161-167. [CrossRef]

27. Dissado, L.A.; Mazzanti, G.; Montanari, G.C. Proposal of a space-charge life model for electrical polymeric insulation aged under AC voltage. In Proceedings of the 1998 IEEE International Symposium on Electrical Insulation, Arlington, VA, USA, 7-10 June 1998; Volume 2, pp. 595-598. [CrossRef]

28. Dissado, L.A.; Mazzanti, G.; Montanari, G.C. The role of trapped space charges in the electrical aging of insulating materials. IEEE Trans. Dielectr. Electr. Insul. 1997, 4, 496-506. [CrossRef]

29. Montanari, G.C.; Pattini, G. Thermal Endurance Evaluation of Insulating Materials: A Theoretical and Experimental Analysis. IEEE Trans. Electr. Insul. 1986, EI-21, 69-77. [CrossRef]

30. Ramteke, P.K.; Ahirwar, A.K.; Shrestha, N.B.; Sanyasi Rao, V.V.S.; Vaze, K.K.; Ghosh, A.K. Thermal ageing predictions of polymeric insulation cables from Arrhenius plot using short-term test values. In Proceedings of the 2010 2nd International Conference on Reliability, Safety and Hazard (ICRESH), Mumbai, India, 14-16 December 2010; pp. 325-328. [CrossRef]

31. Paloniemi, P. Theory of Equalization of Thermal Ageing Processes of Electrical Insulating Materials in Thermal Endurance Tests II: The Theory with Practical Approximations and Application Principles. IEEE Trans. Electr. Insul. 1981, EI-16, 7-17. [CrossRef]

32. Montsinger, V.M. Loading Transformers by Temperature. Trans. Am. Inst. Electr. Eng. 1930, 49, 776-790. [CrossRef]

33. Dakin, T.W. Electrical Insulation Deterioration Treated as a Chemical Rate Phenomenon. AIEE Trans. 1948, 67, 113-122. [CrossRef]

34. Crine, J.-P.; David, E. Influence of mechanical stresses on some electrical properties of polymers. In Proceedings of the Conference on Electrical Insulation and Dielectric Phenomena, St. Petersburg, Russia, 27-30 June 2005; pp. 71-74. [CrossRef]

35. Cygan, P.; Laghari, J.R. A review of electrical and thermal multistress aging models. In Proceedings of the 1990 IEEE International Symposium on Electrical Insulation, Toronto, ON, Canada, 3-6 June 1990; pp. 15-20. [CrossRef]

36. Gjerde, A.C. Multifactor ageing models-Origin and similarities. IEEE Electr. Insul. Mag. 1997, 13, 6-13. [CrossRef]

37. Simoni, L. A General Approach to Endurance of Electrical Insulation under Temperature and Voltage. IEEE Trans. Electr. Insul. 1981, 16, 277-289. [CrossRef]

38. Simoni, L. General Equation of the Decline in the Electric Strength for Combined Thermal and Electrical Stresses. IEEE Trans. Electr. Insul. 1984, 19, 45-52. [CrossRef]

39. Ramu, T.S. On the Estimation of Life of Power Apparatus Insulation under Combined Electrical and Thermal Stress. IEEE Trans. Dielectr. Electr. Insul. 1985, EI-20, 70-78. [CrossRef]

40. Fallou, B.; Burguiere, C.; Morel, J.F. First approach on multiple stress accelerated life testing of electrical insulation. In Proceedings of the Conference on Electrical Insulation and Dielectric Phenomena, Whitehaven, PA, USA, 12-24 October 1979; pp. 621-628.

41. Crine, J.-P. The compensation law and polymer aging and relaxations. In Proceedings of the Conference on Conduction and Breakdown in Solid Dielectrics, Trondheim, Norway, 3-6 June 1989; pp. 321-325. [CrossRef]

42. Grzybowski, S.; Kota, N. Lifetime characteristics of magnet wires under multistress conditions. In Proceedings of the Conference on Electrical Insulation and Dielectric Phenomena, St. Petersburg, Russia, 27-30 June 2005; pp. 605-608. [CrossRef]

43. Weibull Analysis; IEC 61649:2008; International Electrotechnical Commission: Geneva, Switzerland, 2008.

44. Equipment Reliability Testing-Part 4: Statistical Procedures for Exponential Distribution-Point Estimates, Confidence Intervals, Prediction Intervals and Tolerance Intervals; IEC 60605-4:2001; International Electrotechnical Commission: Geneva, Switzerland, 2001.

45. Kacecioglu, D. Reliability Engineering Handbook; Prentice-Hall: Englewood Cliffs, NJ, USA, 1991; ISBN 978-0137723027. 
46. Gubner, J.A. Probability and Random Processes for Electrical and Computer Engineers; Cambridge University Press: Cambridge, UK, 2006; ISBN 978-0521864701.

47. Lewis, P.A.W.; Orav, E.J. Simulation Methodology for Statisticians, Operations Analysts, and Engineers; Wadsworth \& Brooks/Cole: Pacific Grove, CA, USA, 1989; ISBN 0534094503.

48. Brown, R.E. Electric Power Distribution Reliability, 2nd ed.; Marcel Dekker: New York, NY, USA, 2009; ISBN 9780849375675.

49. Electrical Insulation-Thermal Evaluation and Designation; IEC 60085:2007; International Electrotechnical Commission: Geneva, Switzerland, 2007.

50. Badicu, L.V.; Dumitran, L.M.; Notingher, P.V.; Setnescu, R.; Setnescu, T. Mineral oil lifetime estimation using activation energy. In Proceedings of the 2011 IEEE International Conference on Dielectric Liquids, Trondheim, Norway, 26-30 June 2011; pp. 1-4. [CrossRef]

51. Li, Ch.; Tang, T.B. Isoconversion method for kinetic analysis of solid-state reactions from dynamic thermoanalytical data. J. Mater. Sci. 1999, 34, 3467-3470. [CrossRef]

52. Electric Strength of Insulating Materials_Test Methods_Part 1: Tests at Power Frequencies; IEC 60243-1:2013; International Electrotechnical Commission: Geneva, Switzerland, 2013.

53. Liu, H.; Wang, Y.; Yang, Y.; Liao, R.; Geng, Y.; Zhou, L. A Failure Probability Calculation Method for Power Equipment Based on Multi-Characteristic Parameters. Energies 2017, 10, 704. [CrossRef]

54. Zhuang, Q.; Morshuis, P.H.F.; Chen, X.; Meijer, S.; Smit, J.J.; Xu, Z. Life prediction for epoxy resin insulated transformer windings through accelerated aging tests. In Proceedings of the 201010 th IEEE International Conference on Solid Dielectrics, Potsdam, Germany, 4-9 July 2010; pp. 1-4. [CrossRef]

(C) 2017 by the authors. Licensee MDPI, Basel, Switzerland. This article is an open access article distributed under the terms and conditions of the Creative Commons Attribution (CC BY) license (http:/ / creativecommons.org/licenses/by/4.0/). 